\title{
A Review of Neurological Manifestation Caused by Biological Warfare Agents and their Therapeutic Approaches
}

\section{Arash Alaeddini ${ }^{*}$, Mahdi Hosseinzadeh ${ }^{1}$, Salman Mandani²}

${ }^{1}$ Seraj Center, Passive Defense Faculty and Research Center, Imam Hussein Comprehensive University, Tehran, Iran ${ }^{2}$ Department of Biology, Faculty of Science, Imam Hussein Comprehensive University, Tehran, Iran

\section{A BSTRACT}

Introduction: Deliberate bio-terrorism is deliberated use of bacteria, viruses, toxins or other biological agents (in the form of natural or modified forms) that causes destruction or damage to human, animal, vegetable, natural resources and environmental, industrial or agricultural infrastructure. A wide range of factors can potentially be used as weapons, however, only some of those substances are used as weapon. Various neurological symptoms could be caused by exposure to different biological warfare. Early detection of biological contamination reduces their destructive effects. Early access to appropriate treatment is essential for prevention of damages to the nervous system. Training of medical staffs on the management of neurological symptoms of victims exposed to biological warfare is a crucial for favorable prognosis. Conclusion: Improving our knowledge of clinical syndromes and diseases caused by bio-terrorism is helpful to differentiate from other neurological disorders.

*Corresponding Author: Arash Alaeddini

E-mail: arash553-s@yahoo.com 


\section{مرورى بر تظاهرات عصبى ناشى از عوامل جنَى ميكروبى و رويكردهاى درمانى آنها}

$$
\text { آرش علاءالدينى '":، مههدى حسينزاده'، سلمان ماندنى ' }
$$

'مركز سراج، دانشكده و يُوهشكده بِافند غيرعامل، دانشعاه جامع امام حسين (ع)، تهران، ايران

rكروه زيستشناسى، دانشكده علوم، دانشخاه جامع امام حسين (ع)، تهران، ايران

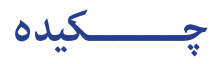

مقدمه: بيوتروريسم عمدى استفاده متعمدانه از باكترىها، ويروسها، سموم يا ساير عوامل زيستى (به

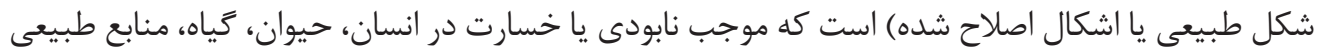

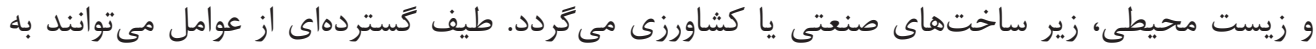

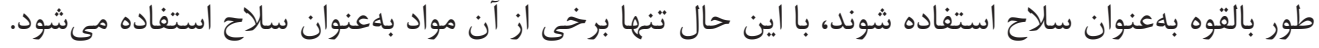

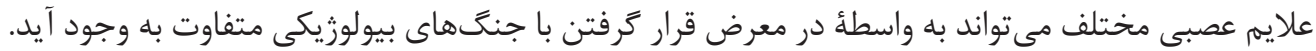

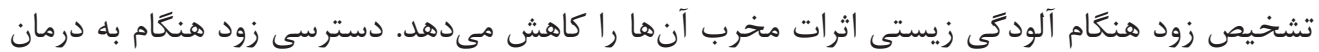

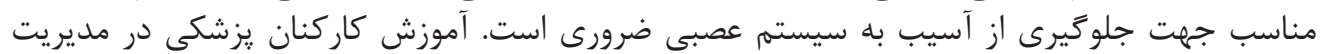

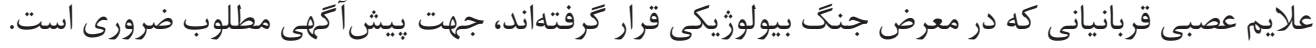

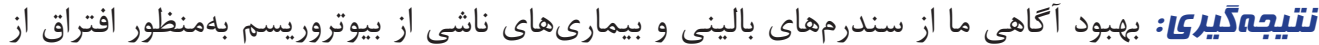
ساير اختلالات عصبى مفيد است مبود 


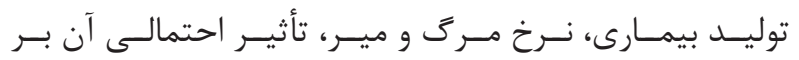

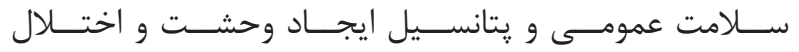
اجتماعسى صـورت كرفتــه اسـت (1) ، 11).

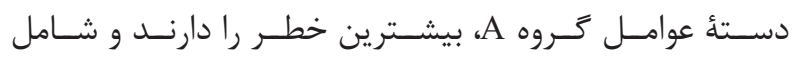

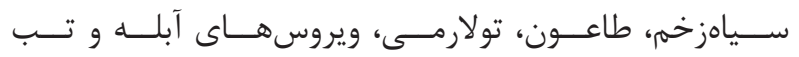

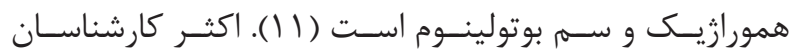

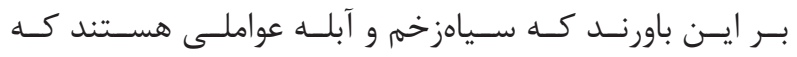

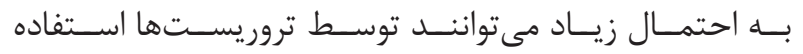

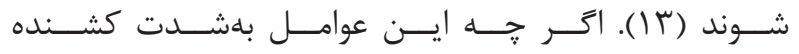

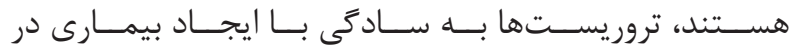

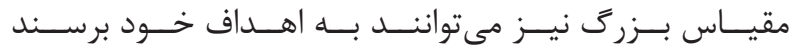

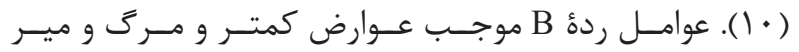

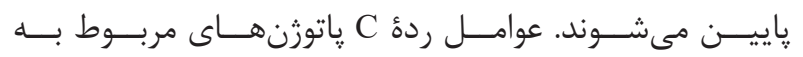

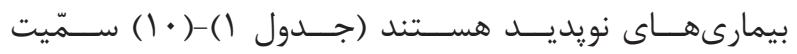

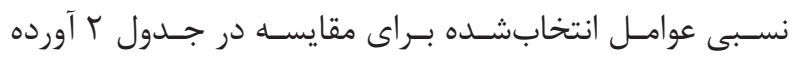

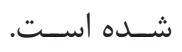

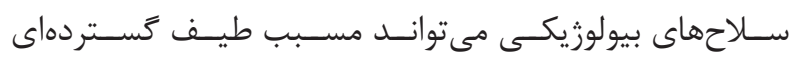

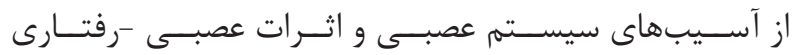

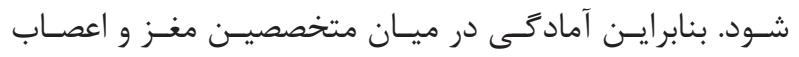

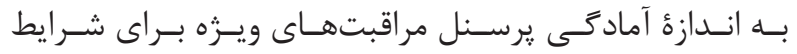

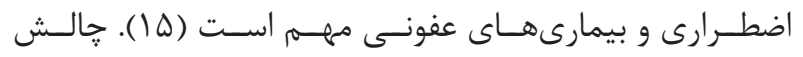

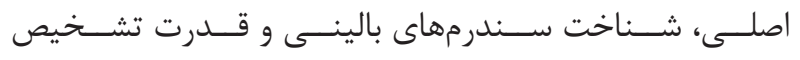

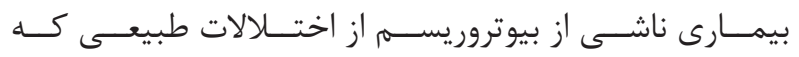

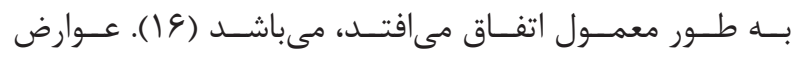

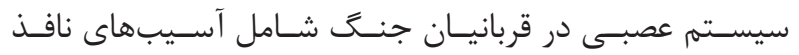

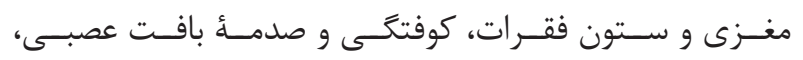

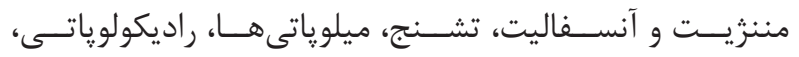

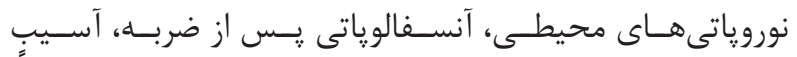

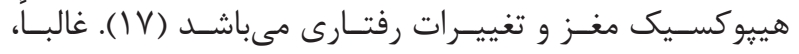

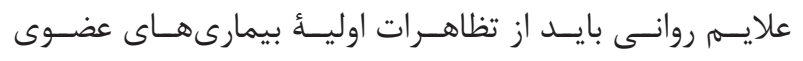

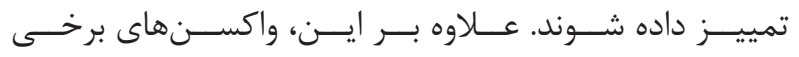

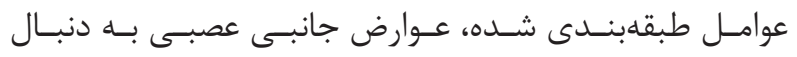

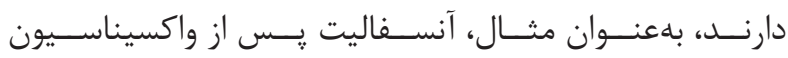

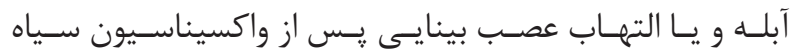

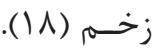

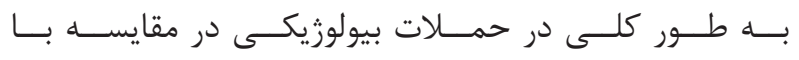

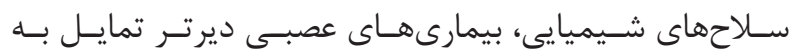

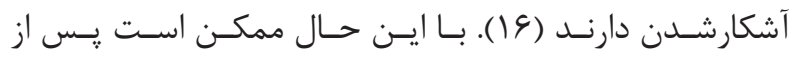

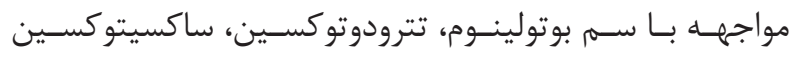

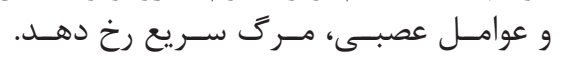

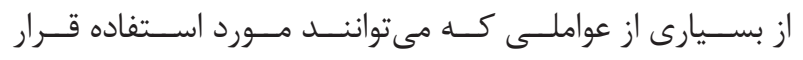

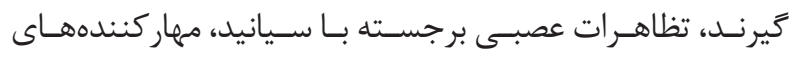

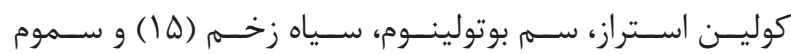

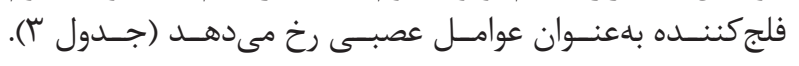

\section{مقدمه}

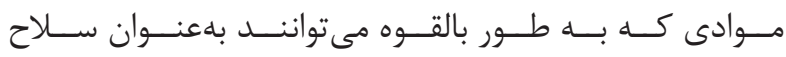

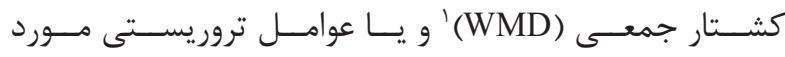

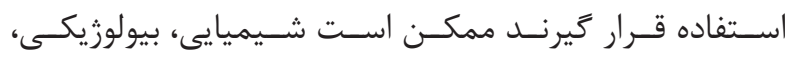

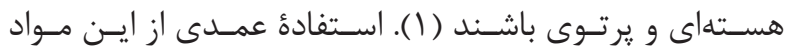

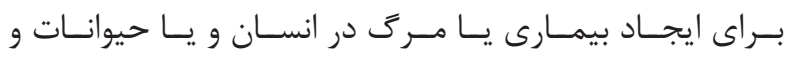

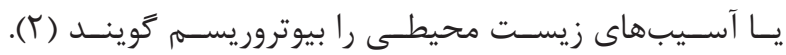

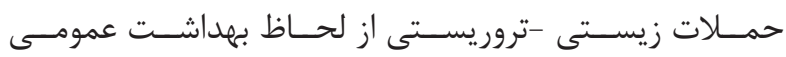

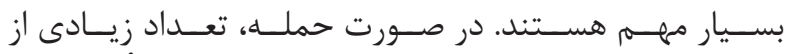

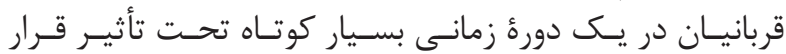

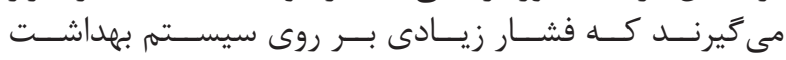

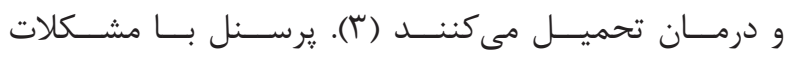

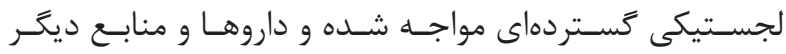

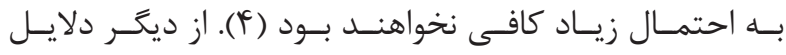

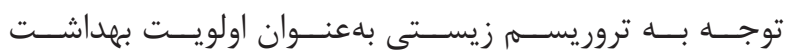

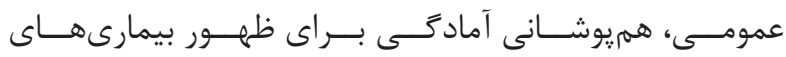

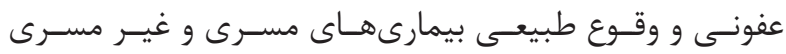

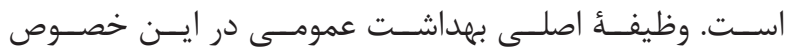

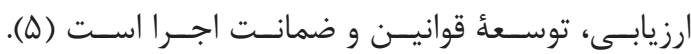

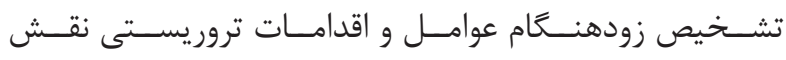

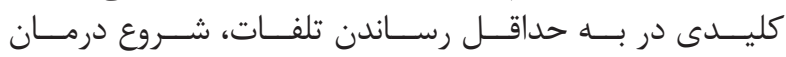

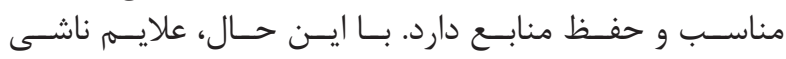

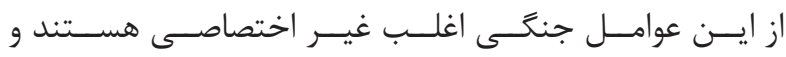

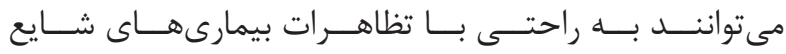

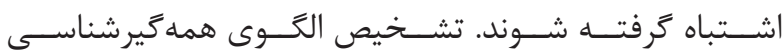

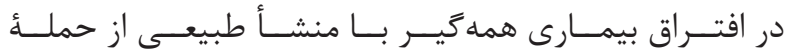

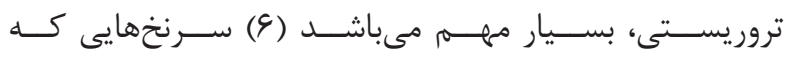

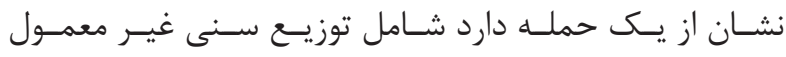

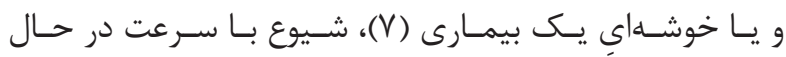

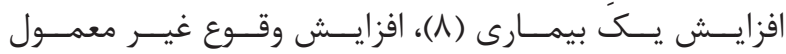

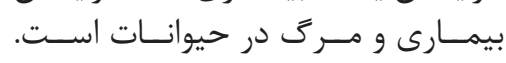

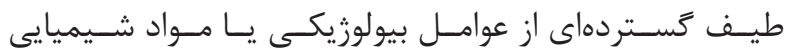

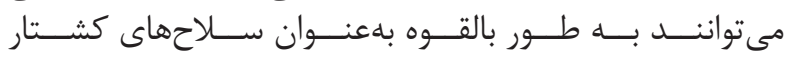

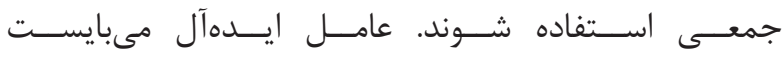

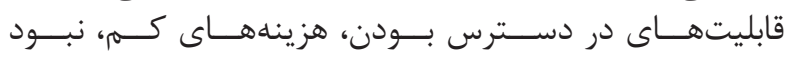

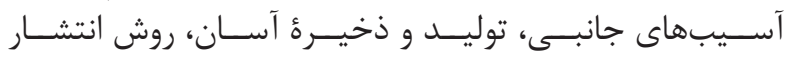

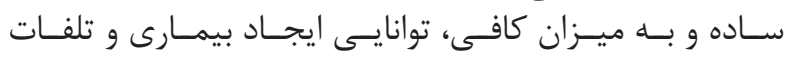

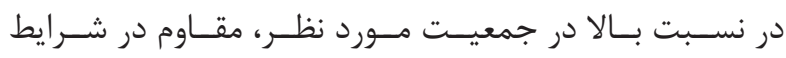

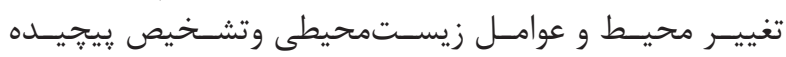

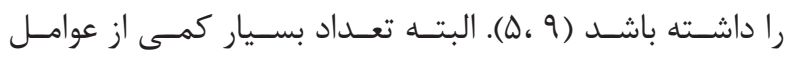

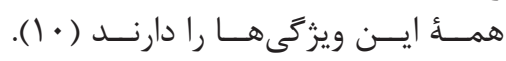

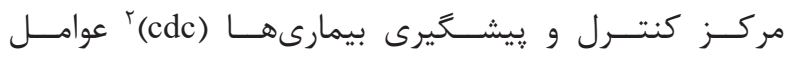

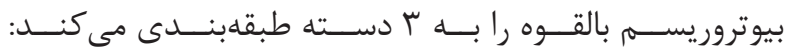

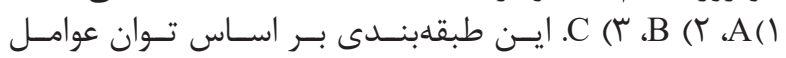

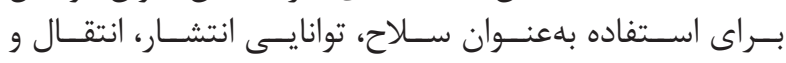


جدول ا- دستهبندى عوامل تروريسم زيستى (f).

\begin{tabular}{|lll|}
\hline \multicolumn{3}{|c}{ Centers for Disease Control and Prevention Categories of Bioterrorism Agents/Diseases } \\
\hline Category A & Category B & Category C \\
Anthrax & Brucellosis (Brucella species) & $\begin{array}{l}\text { Emerging infectious diseases (e.g., Nipah viru: } \\
\text { hantavirus) }\end{array}$ \\
Botulism & Epsilon toxin of Clostridium perfringens & \\
Plague & Food safety threats (e.g., Salmonella & Emerging future toxins \\
Smallpox & species) & \\
Tularemia & Glanders (Burkholderia mallei) & \\
Viral hemorrhagic & Melioidosis (Burkholderia pseudomallei) & \\
fevers & Psittacosis (Chlamydia psittaci) & \\
& & \\
& Q fever (Coxiella burnetii) & \\
& Ricin toxin from Ricinus communis & \\
& Staphylococcal enterotoxin B & \\
& Typhus fever (Rickettsia prowazekii) & \\
& Viral encephalitides (alphaviruses) & \\
& Water safety threats (e.g., vibrio cholerae) & \\
&
\end{tabular}

جدول ץ- سمّيت نسبى عوامل انتخاب شده (f) (1).

\begin{tabular}{|lll|}
\hline \multicolumn{3}{|c|}{ Relative toxicity of selected toxins and agents in mice } \\
\hline Toxin/Agent & $\mathrm{LD} 50(\mu \mathrm{g} / \mathrm{kg})$ & Source \\
Botulinum toxin & 0.001 & Clostridium botulinum (bacterium) \\
Shiga toxin & 0.002 & Shigella dysenteriae (bacterium) \\
Tetanus toxin & 0.002 & Clostridium tetani (bacterium) \\
Diphtheria toxin & 0.10 & Clostridium diphtheria (bacterium) \\
Ciguatoxin & 0.40 & Fish/marine dinoflagellate \\
Clostridium perfringens toxins & $0.1-0.5$ & C. perfringens (bacterium) \\
Ricin & 3.0 & Castor bean (plant) \\
Tetrodotoxin & 8.0 & Puffer fish \\
Saxitoxin & 10.0 (inhaled 2.0) & Marine dinoflagellate \\
VX & 15.0 & Chemical agent \\
Anatoxin A & 50.0 & Blue-green alga \\
Soman (GD) & 64.0 & Chemical agent \\
Sarin (GB) & 100.0 & Chemical agent \\
\hline
\end{tabular}


جدول ץ- - تشخيص تفريقى عوامل با علايم عصبى برجسته (f).

\begin{tabular}{|c|c|c|c|c|c|}
\hline \multirow[b]{2}{*}{ Agent } & \multicolumn{5}{|c|}{ Clinical Features } \\
\hline & Symptom onset after exposure & Motor/sensory & Cranial nerves & Autonomic symptoms & CNS symptoms \\
\hline Botulinum toxin & $2 \mathrm{hrs}-8$ days & $\begin{array}{l}\text { Descending, symmetric, } \\
\text { flaccid paralysis; begins in } \\
\text { bulbar muscles } \\
\text { No sensory symptoms }\end{array}$ & $\begin{array}{l}\text { Palsies early and } \\
\text { prominent: diplopia, } \\
\text { dysarthria, } \\
\text { dysphagia }\end{array}$ & Mydriasis, dry mouth, constipation & Mental status intact \\
\hline Seafood neurotoxin & Minutes to hours & $\begin{array}{l}\text { Severe, rapidly ascending } \\
\text { paralysis } \\
\text { Paresthesias prominent, } \\
\text { start periorally and spread } \\
\text { to limbs }\end{array}$ & $\begin{array}{l}\text { Bulbar involvement } \\
\text { common }\end{array}$ & Hypersalivation, diaphoresis, GI distress & $\begin{array}{l}\text { Anxiety; convulsions } \\
\text { possible }\end{array}$ \\
\hline $\begin{array}{l}\text { Nerve agents } \\
\text { (Organophosphates, } \\
\text { GA, GB, GD, GF, } \\
\text { VX) }\end{array}$ & Seconds to minutes & $\begin{array}{l}\text { Dose dependent from } \\
\text { skeletal muscle weakness } \\
\text { with fasciculations to } \\
\text { paralysis }\end{array}$ & Not prominent & $\begin{array}{l}\text { Exocrine secretions early and prominent: } \\
\text { SLUDGE: salivation, lacrimation, urination, } \\
\text { defecation, GI hypermotility, emesis; miosis, } \\
\text { rhinorrhea }\end{array}$ & $\begin{array}{l}\text { Dose-dependent: } \\
\text { irritability, headache, } \\
\text { convulsions, coma }\end{array}$ \\
\hline $\begin{array}{l}\text { Anticholinergic } \\
\text { poisoning } \\
\text { (Atropine) }\end{array}$ & Minutes to hours & none & none & $\begin{array}{l}\text { Cutaneous vasodilation, anhidrosis, hyperthermia, } \\
\text { nonreactive mydriasis, urinary retention, } \\
\text { tachycardia }\end{array}$ & $\begin{array}{l}\text { Anxiety, agitation, } \\
\text { confusion, delirium, } \\
\text { hallucinations, seizure, } \\
\text { coma }\end{array}$ \\
\hline Cyanides & Minutes & $\begin{array}{l}\text { Rhabdomyolysis - may } \\
\text { lead to mild weakness }\end{array}$ & Not commonly & $\begin{array}{l}\text { Mucosal irritation, GI upset, arrhythmias,skin } \\
\text { flushing, pupillary light reflex delayed }\end{array}$ & $\begin{array}{l}\text { Headache, dizziness, } \\
\text { drowsiness, seizures, } \\
\text { coma }\end{array}$ \\
\hline Anthrax & $\begin{array}{l}\text { Hours to weeks for } \\
\text { systemic pulmonary } \\
\text { manifestation; neurological } \\
\text { manifestation as second stage }\end{array}$ & $\begin{array}{l}\text { Long-tract signs, } \\
\text { hyperreflexia, myoclonus, } \\
\text { rigidity }\end{array}$ & Not prominent & Fever, nausea, vomiting & $\begin{array}{l}\text { Headache, confusion, } \\
\text { seizures, stupor, coma; } \\
\text { hemorrhagic meningitis }\end{array}$ \\
\hline
\end{tabular}

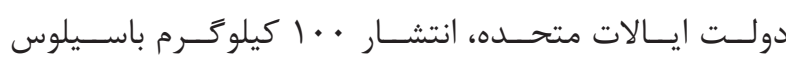

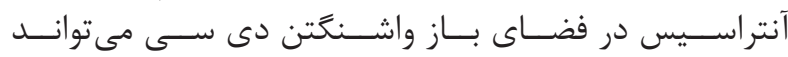

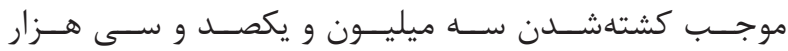

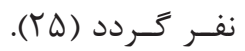

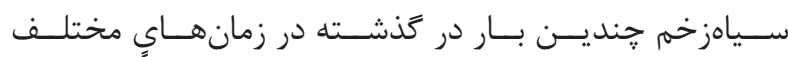

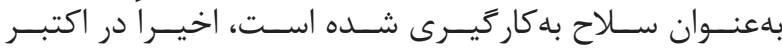

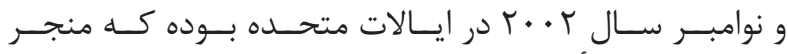

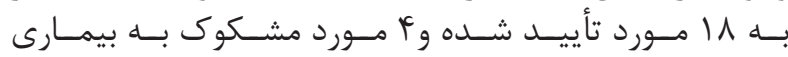

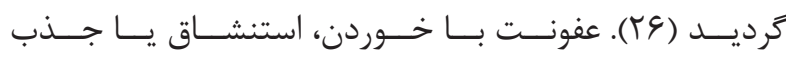

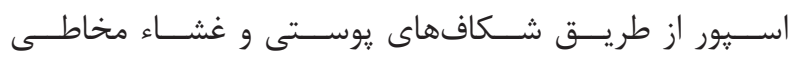

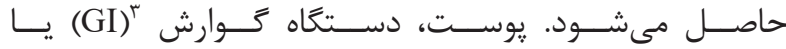

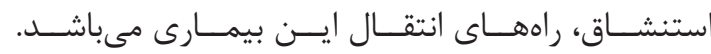

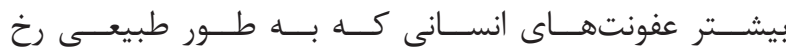

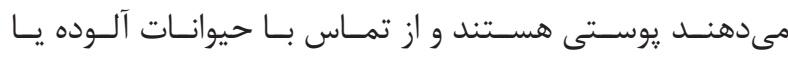

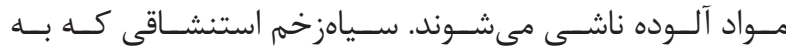

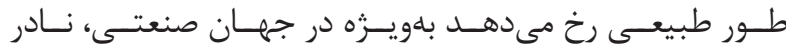

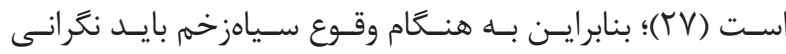

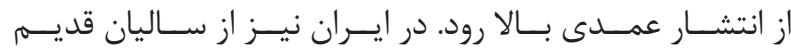

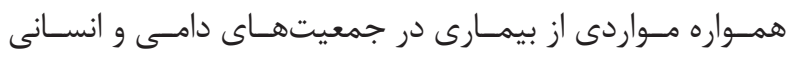

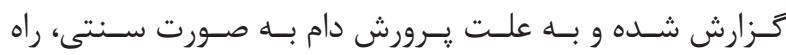

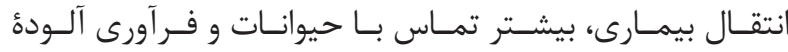

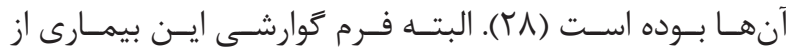

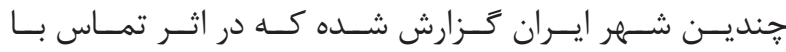

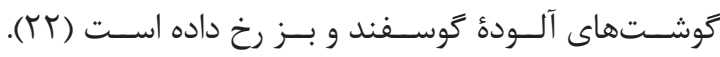

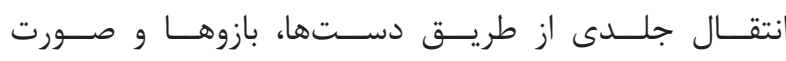

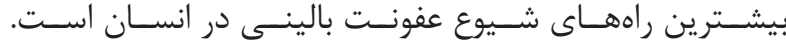

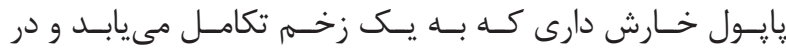

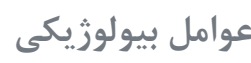

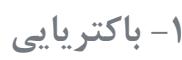

(-1) (A سياهزخم (رده)

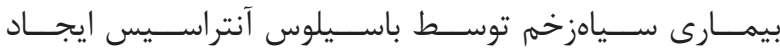

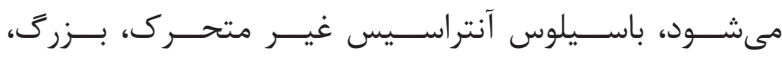

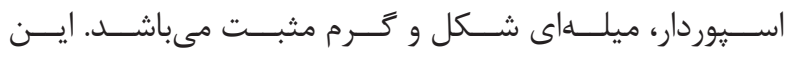

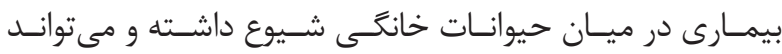

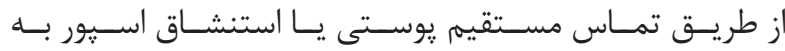

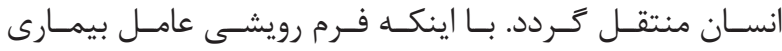

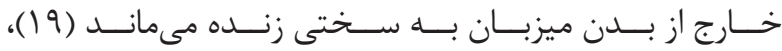

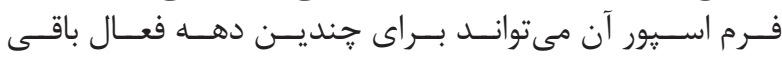

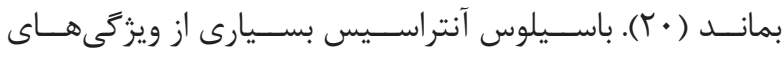

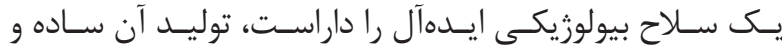

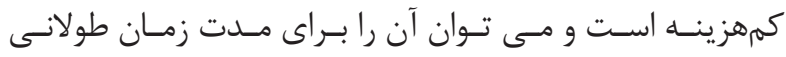

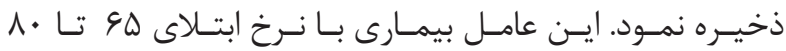

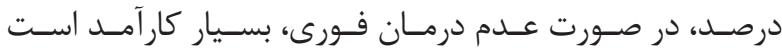

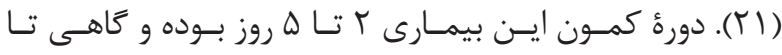

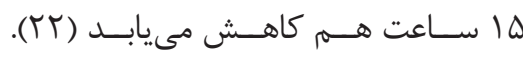

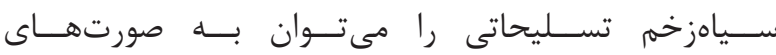

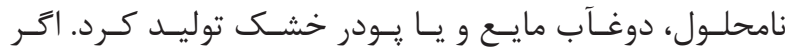

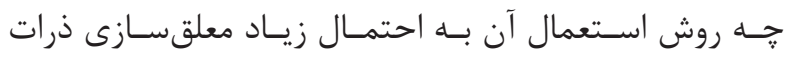

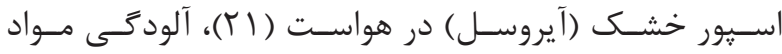

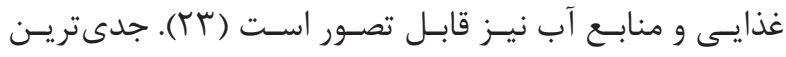

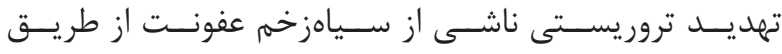

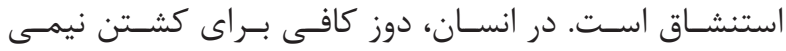

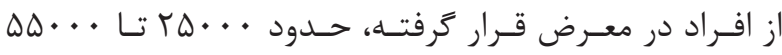

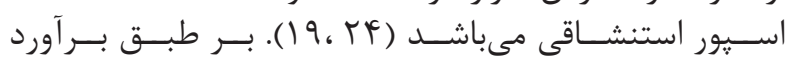

${ }^{3}$ Gastrointestinal 


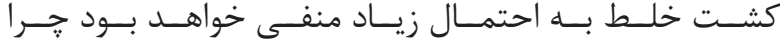

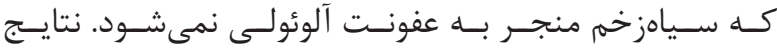

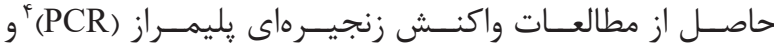

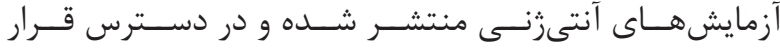

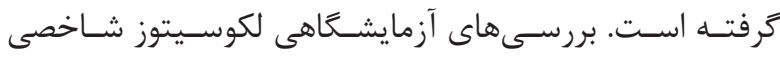

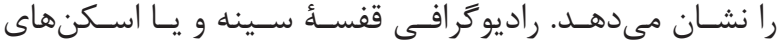

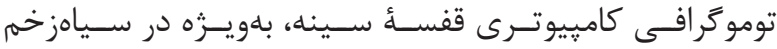

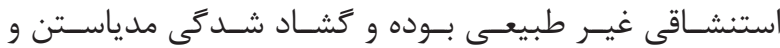

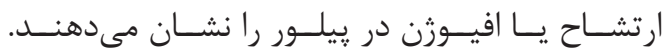

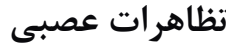

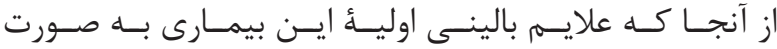

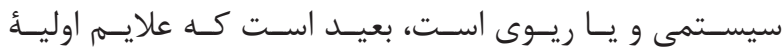

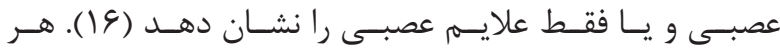

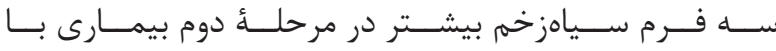

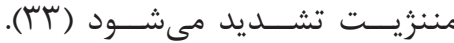

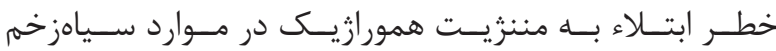

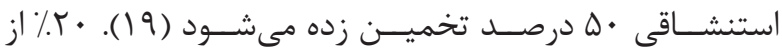

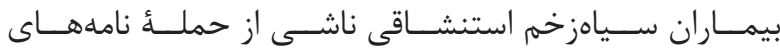

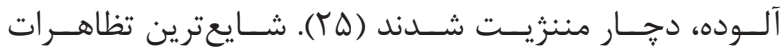

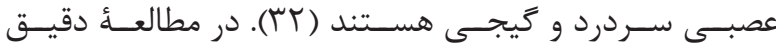

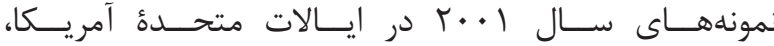

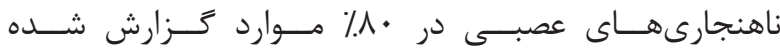

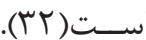

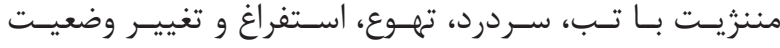

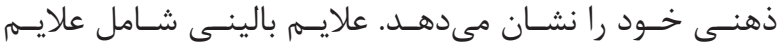

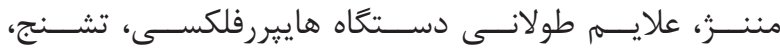

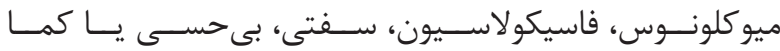

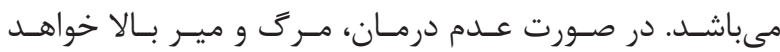

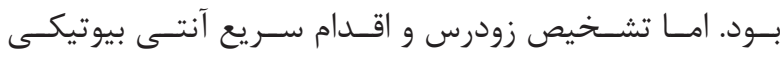

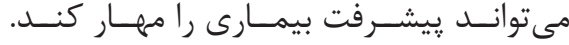

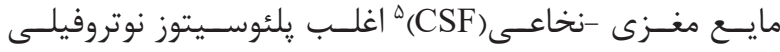

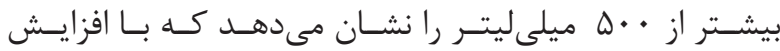

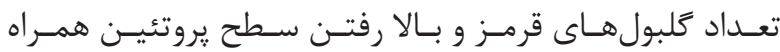

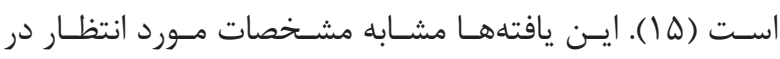

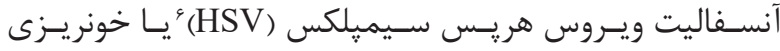
زيـر عنكبوتيـه هسـتند (بآ).

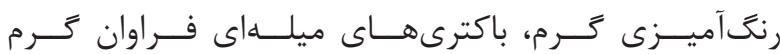

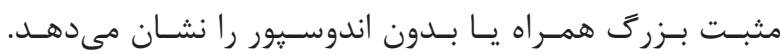

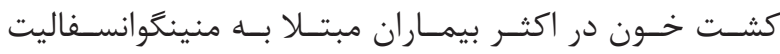

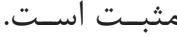

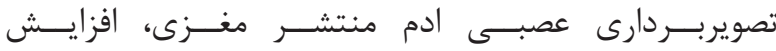

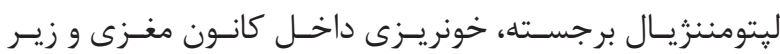

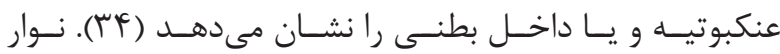

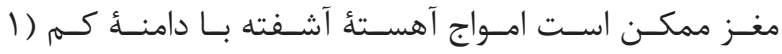

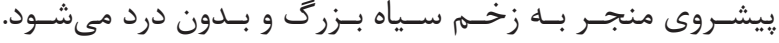

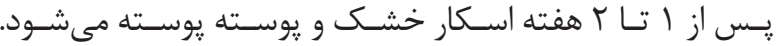

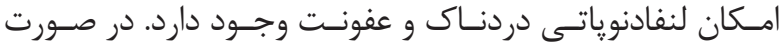

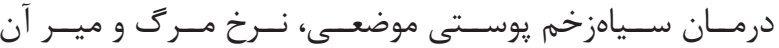

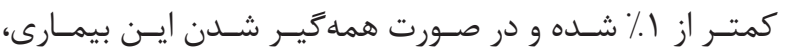

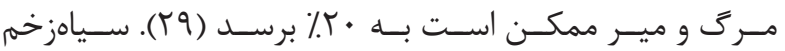

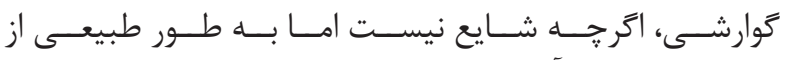

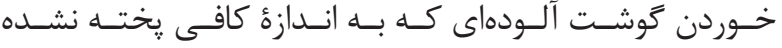

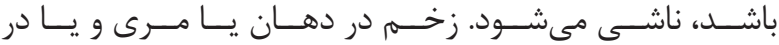

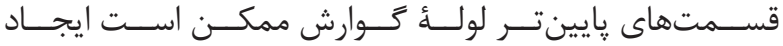

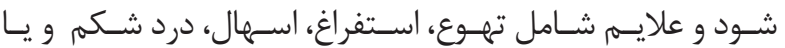

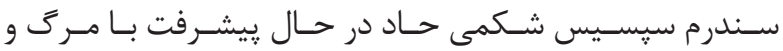

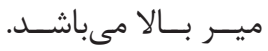

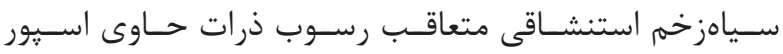

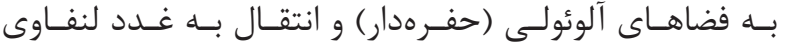

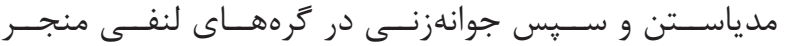

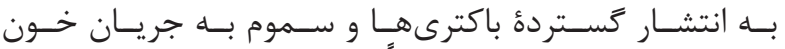

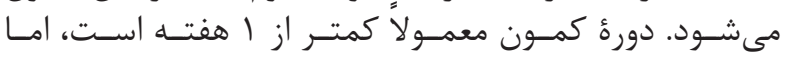

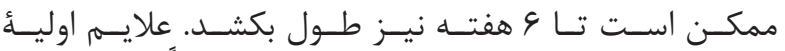

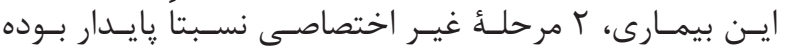

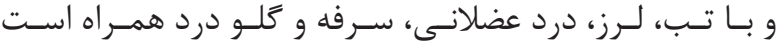

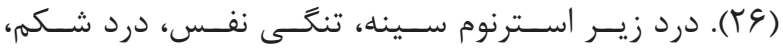

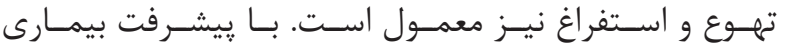

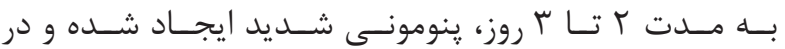

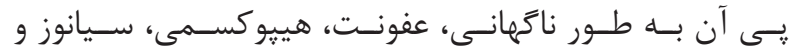

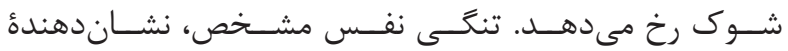

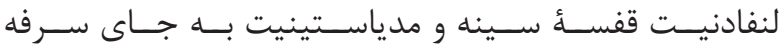

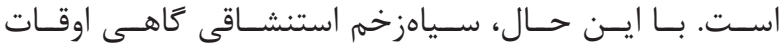

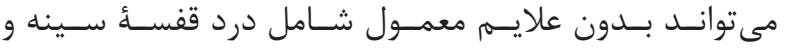

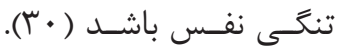

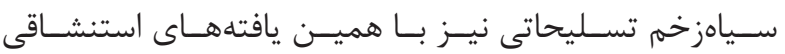

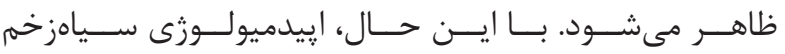

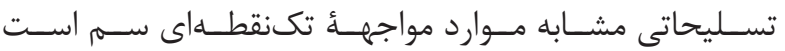

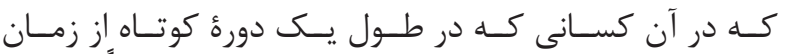

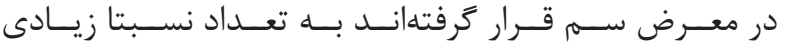

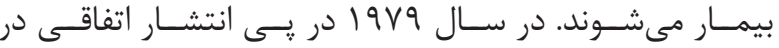

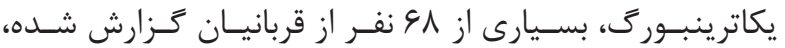

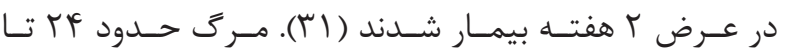

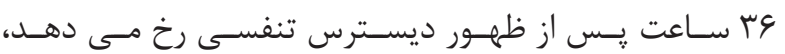

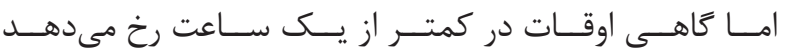

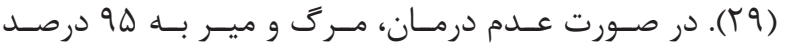

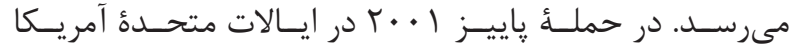

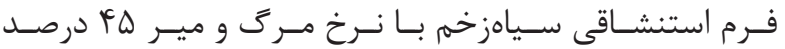

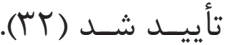

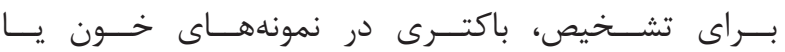

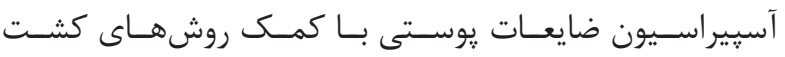

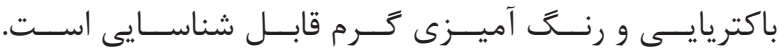

${ }^{4}$ Polymerase chain reaction

${ }^{6}$ Herpes simplex virus 


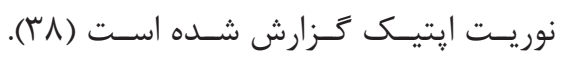

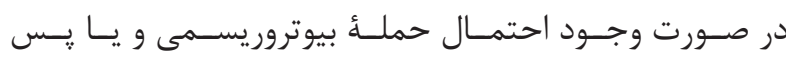

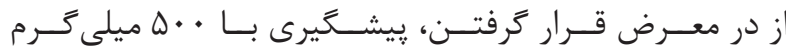

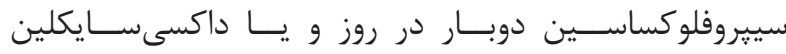

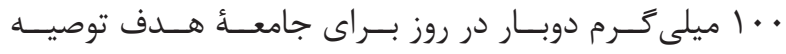

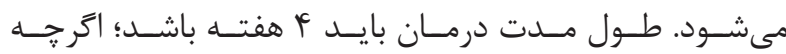

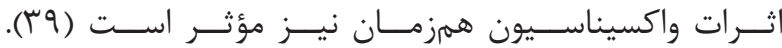

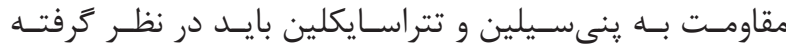

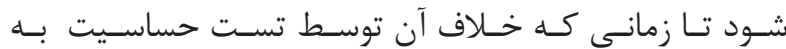

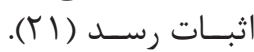

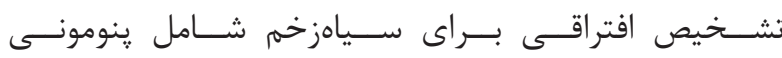

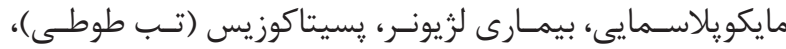

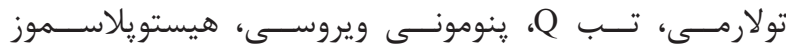

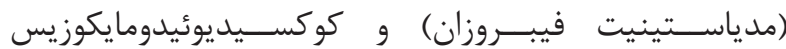

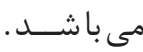

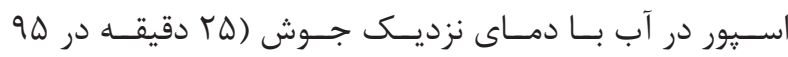

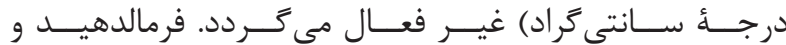

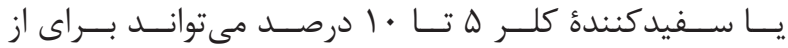

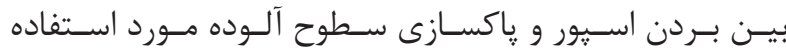

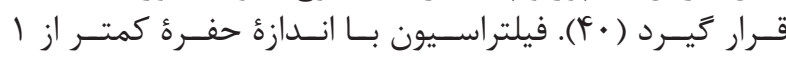

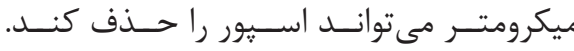

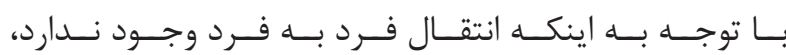

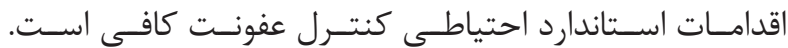

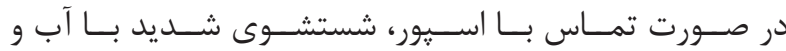

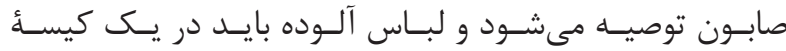

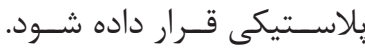

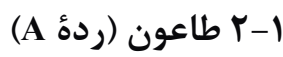

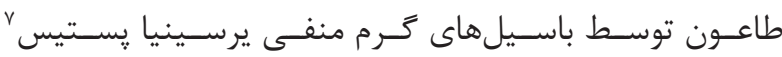

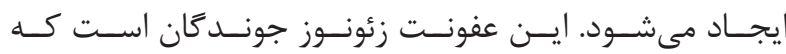

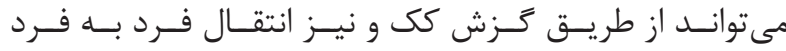

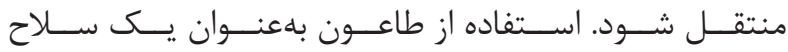

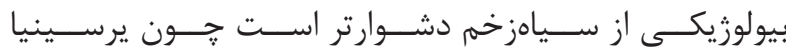

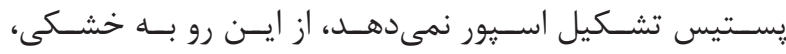

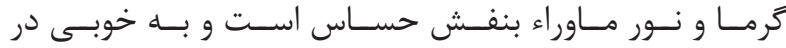

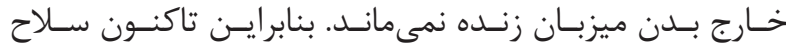

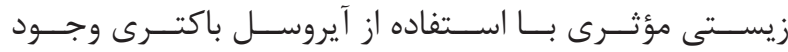

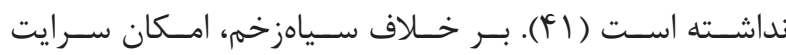

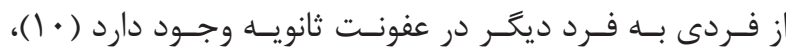

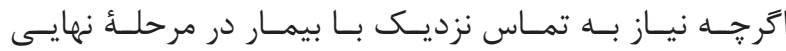

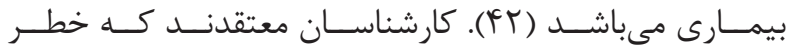

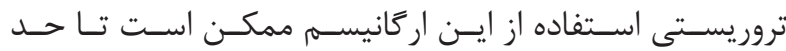

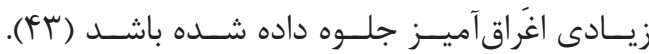

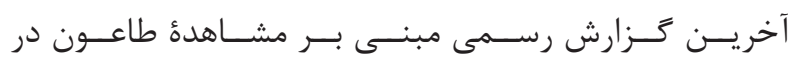

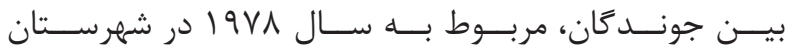

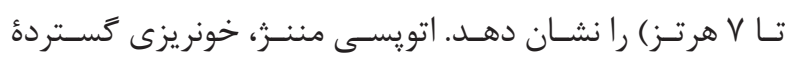

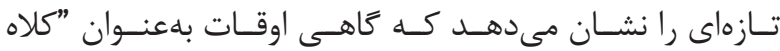

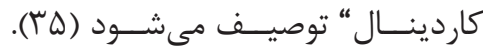

\section{كنترل و درمان}

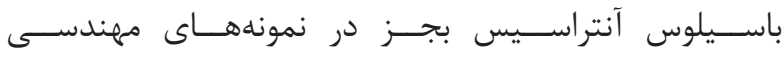

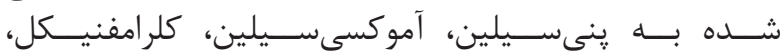

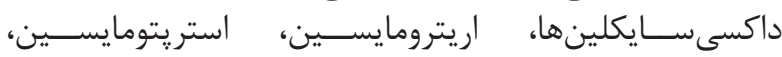

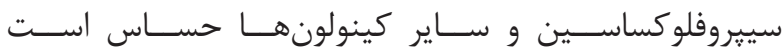

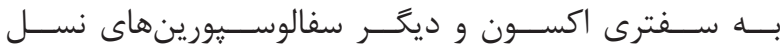

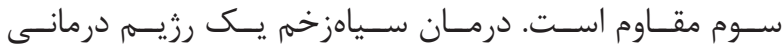

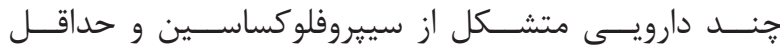

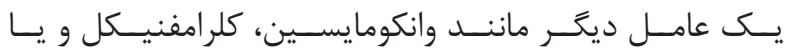

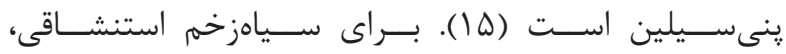

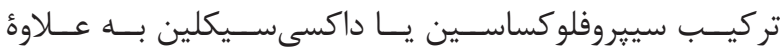

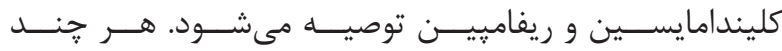

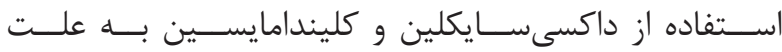

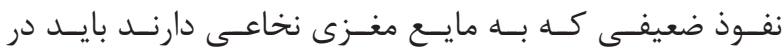

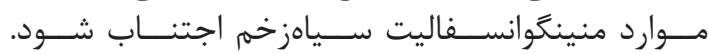

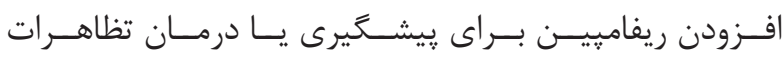

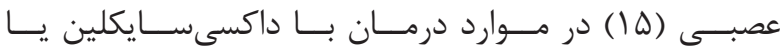

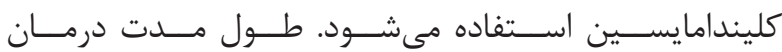

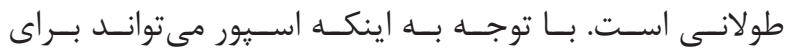

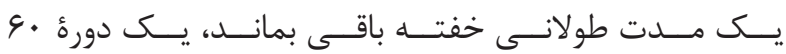

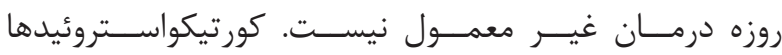

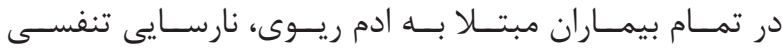

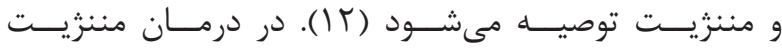

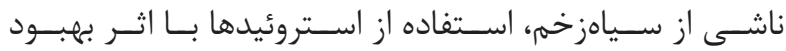

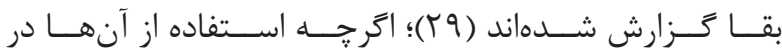

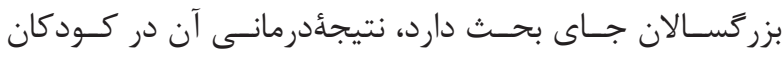

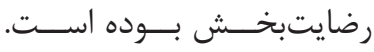

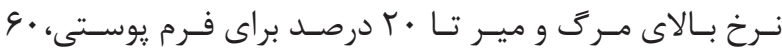

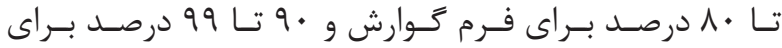

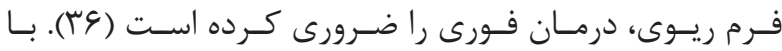

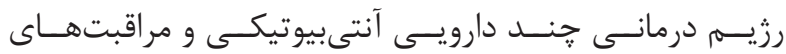

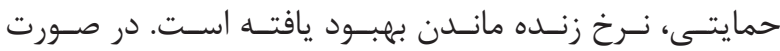

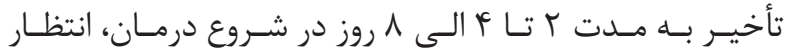

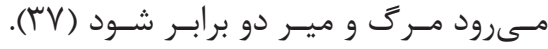

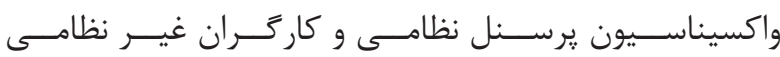

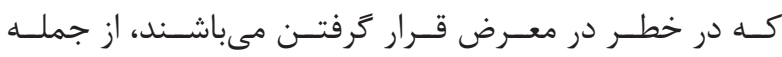

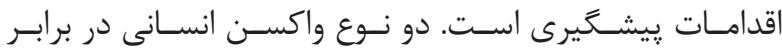

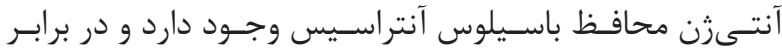

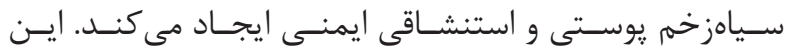

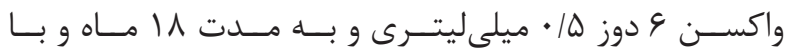

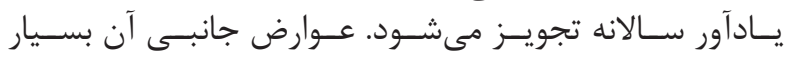

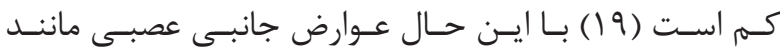




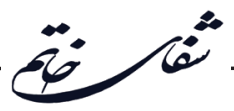

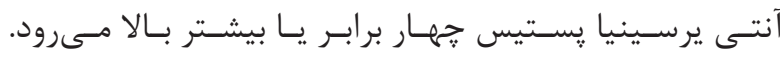

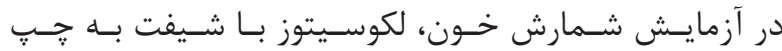

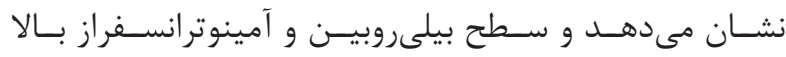

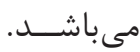

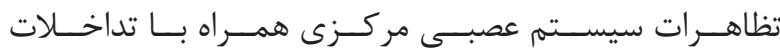

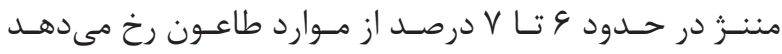

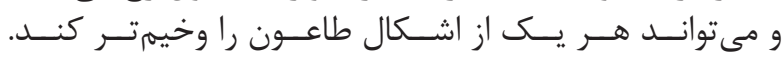

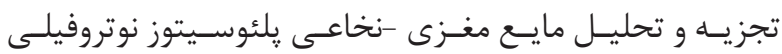

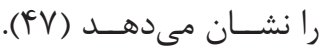

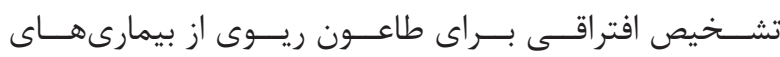

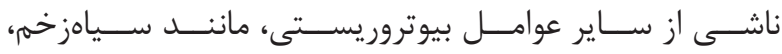

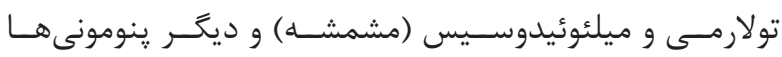

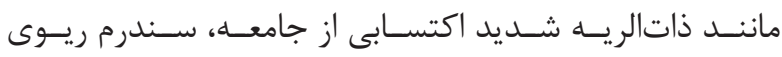

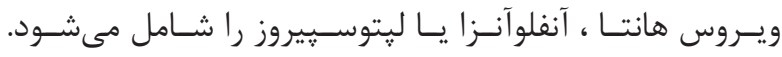

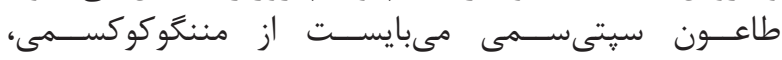

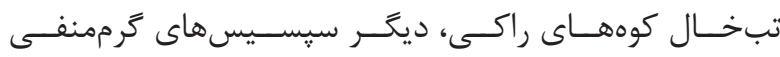

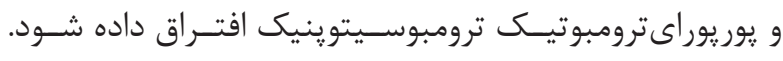

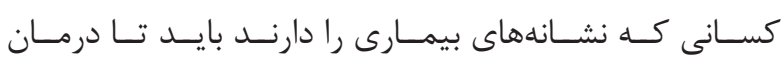

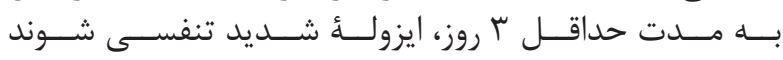

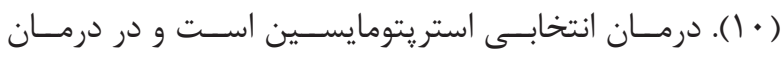

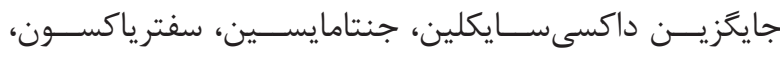

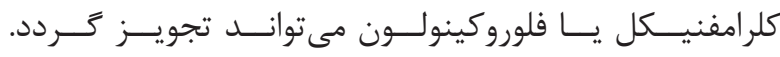

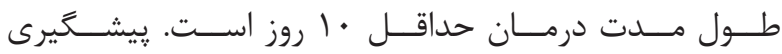

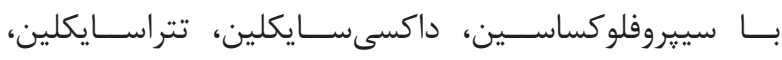

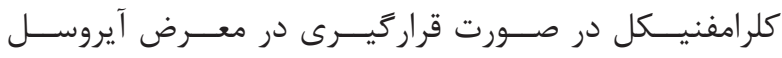

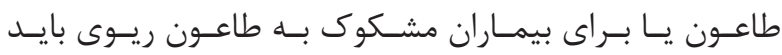

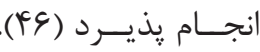

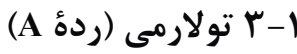

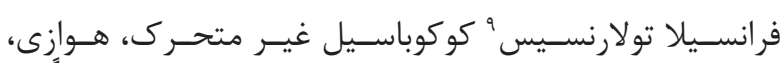

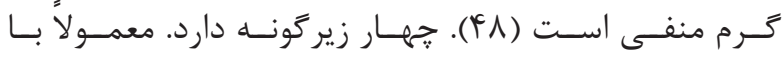

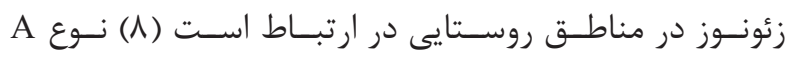

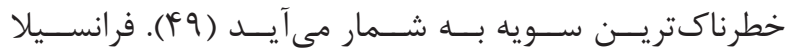

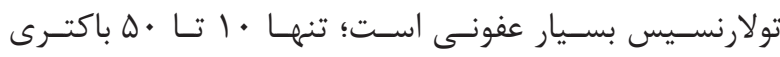

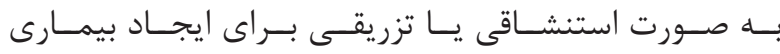

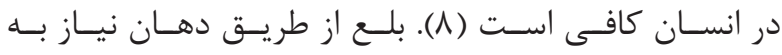

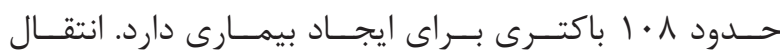

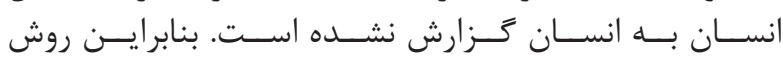

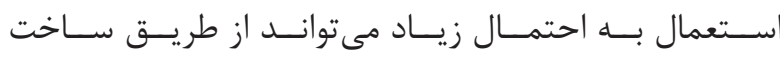

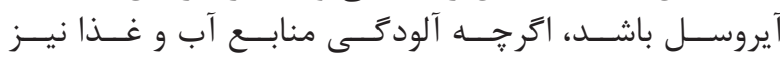

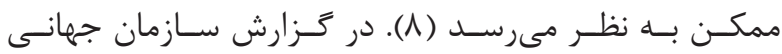

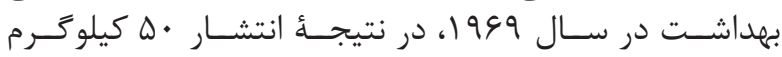

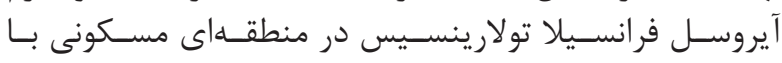

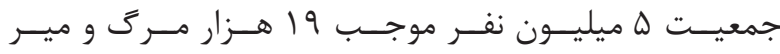

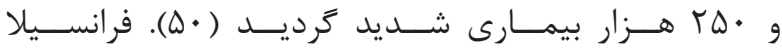

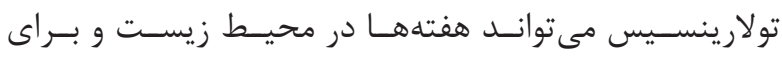

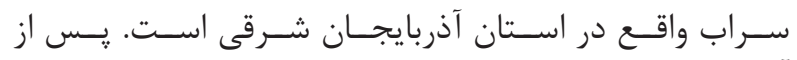

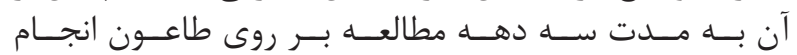

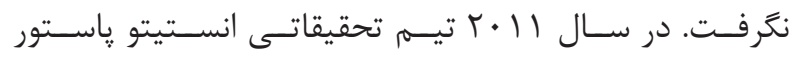

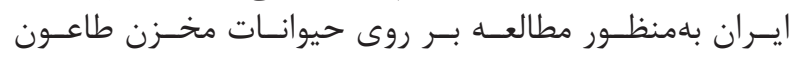

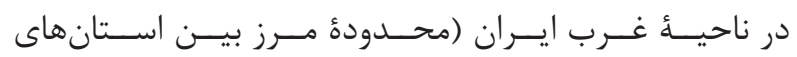

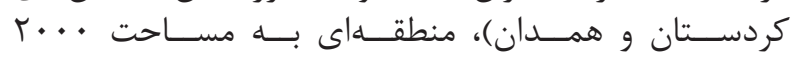

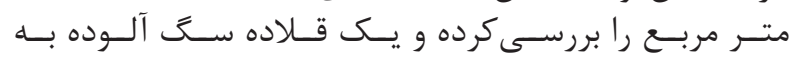

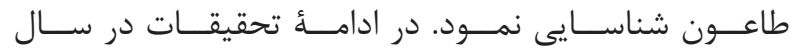

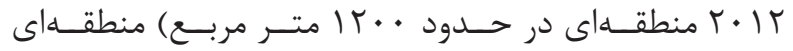

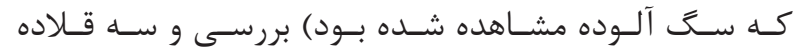

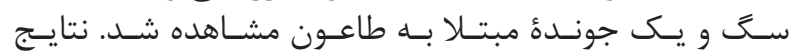

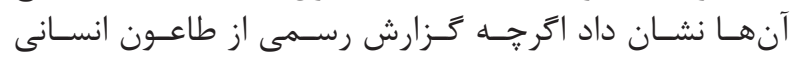

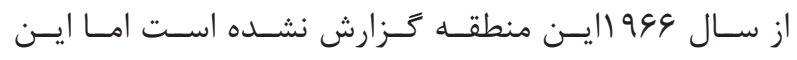

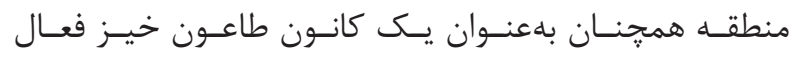

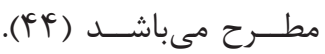

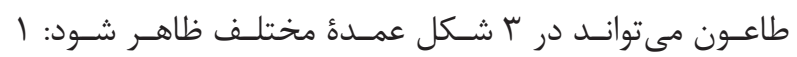

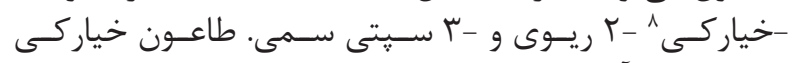

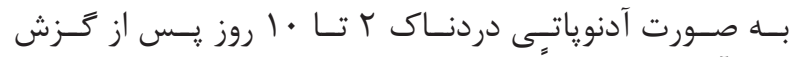

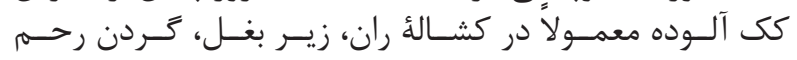

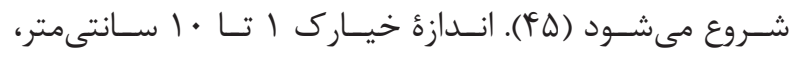

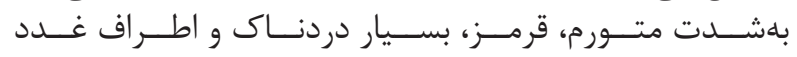

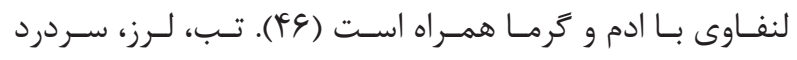

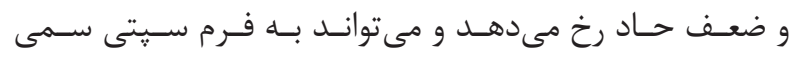

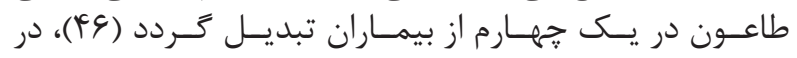

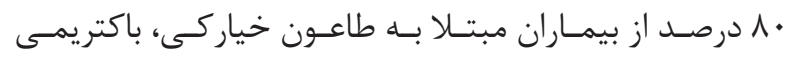

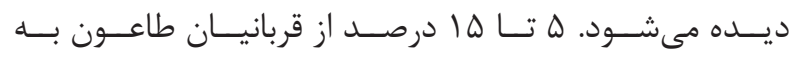

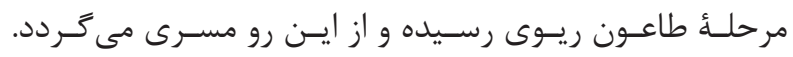

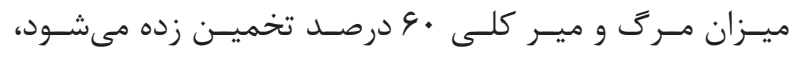

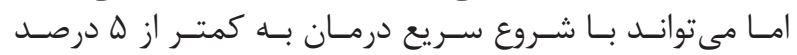

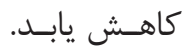

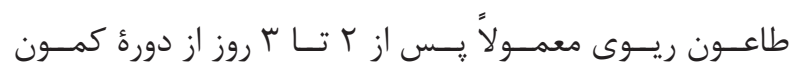

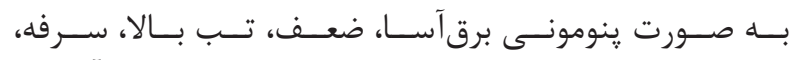

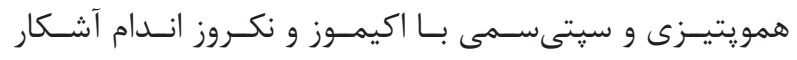

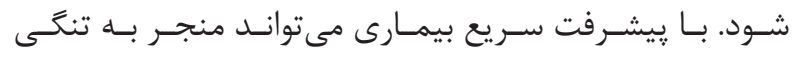

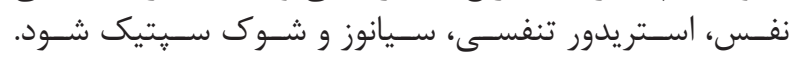

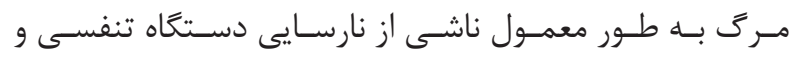

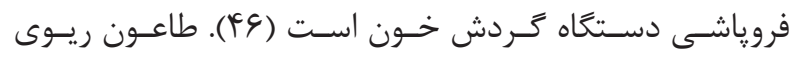

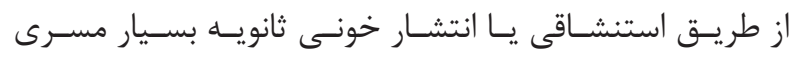

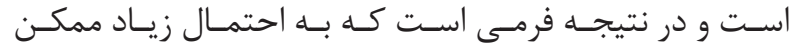

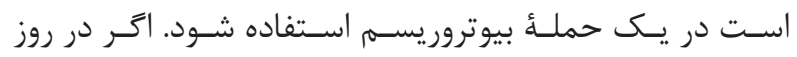

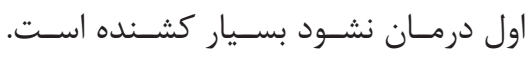

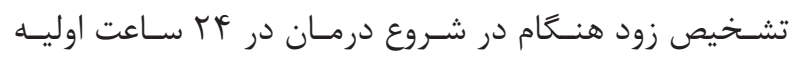

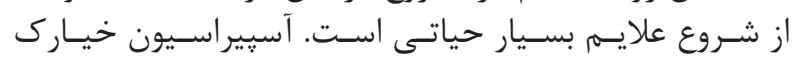

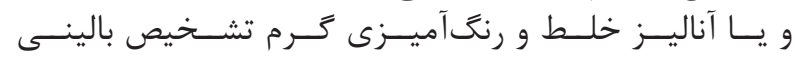

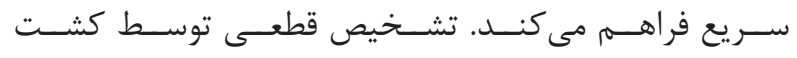

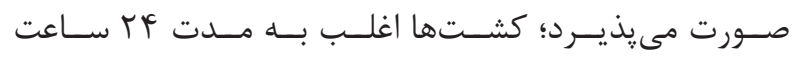

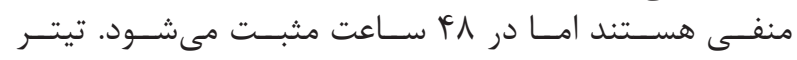




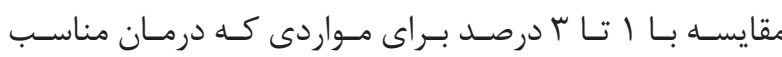

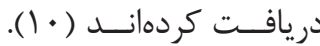

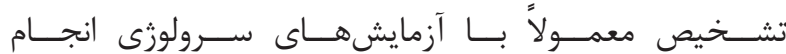

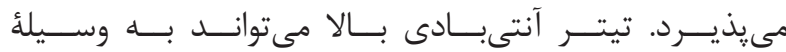

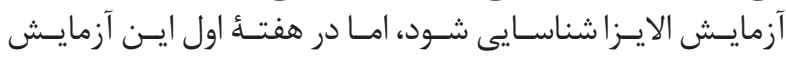

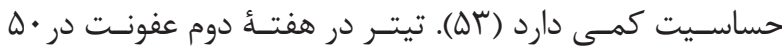

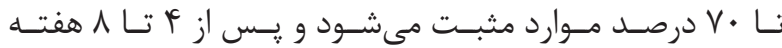

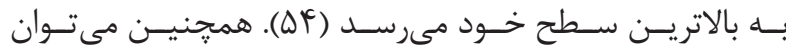

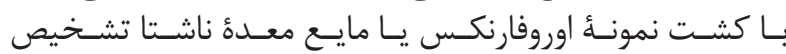

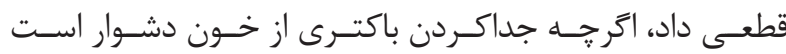

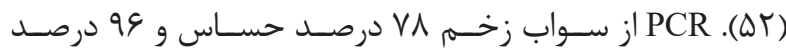
اختصاصسى اسـت (لهـ (ه).

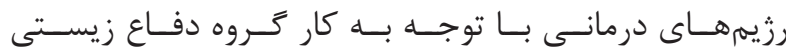

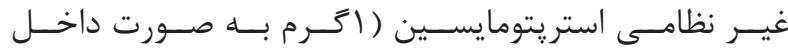

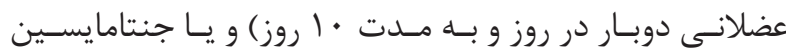

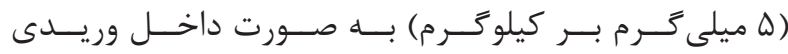

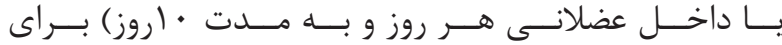

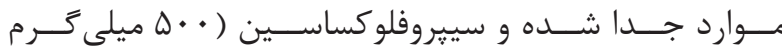

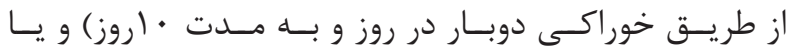

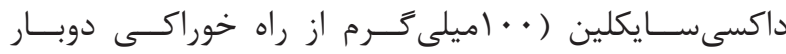

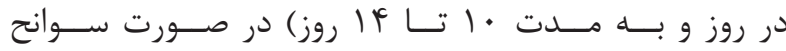

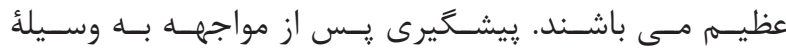

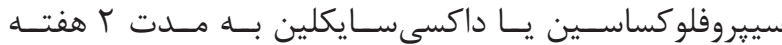

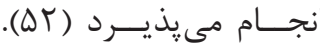

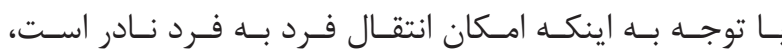

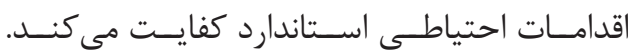

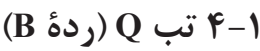

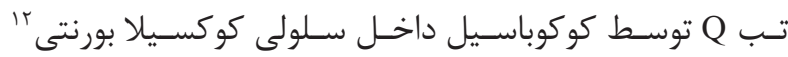

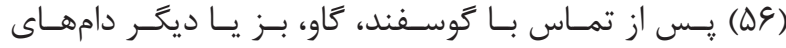

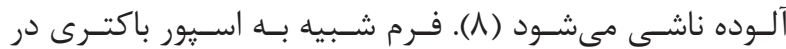

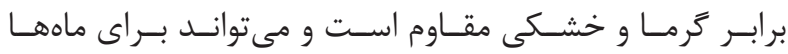

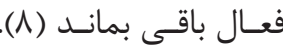

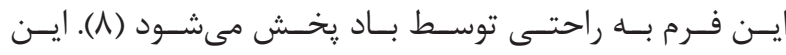

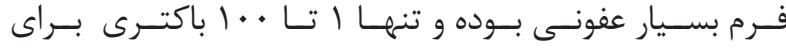

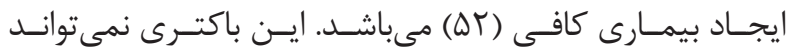

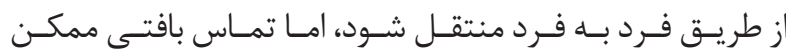

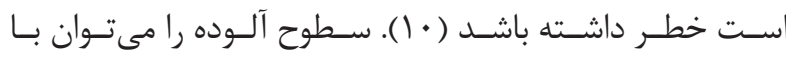

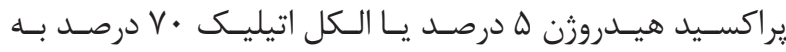

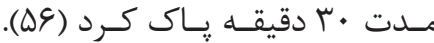

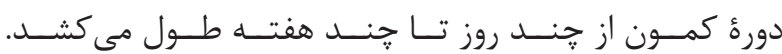

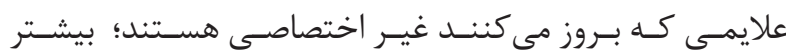

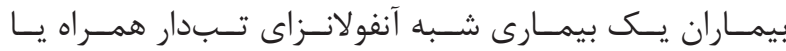

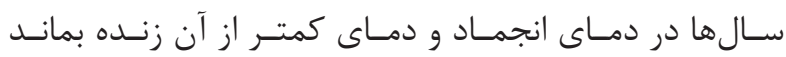

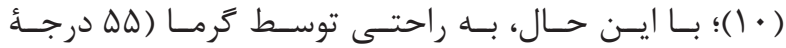

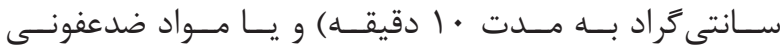

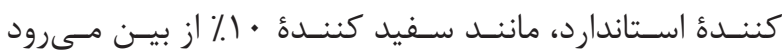

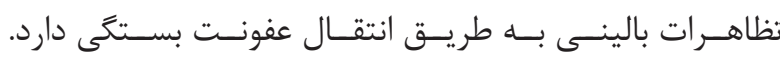

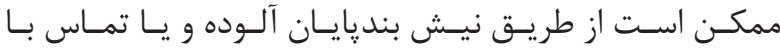

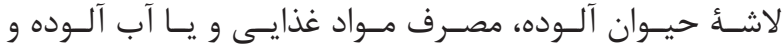

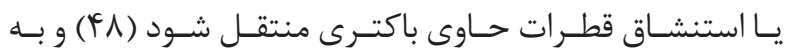

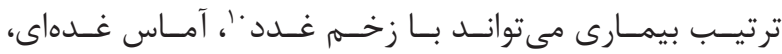

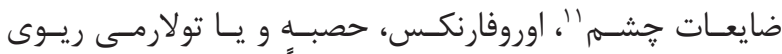

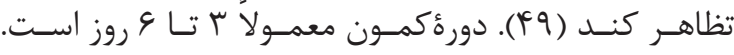

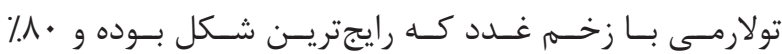

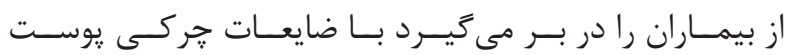

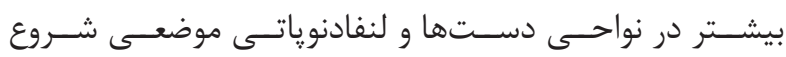

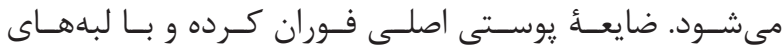

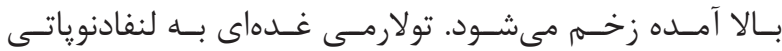

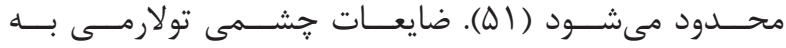

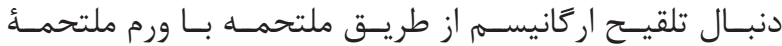

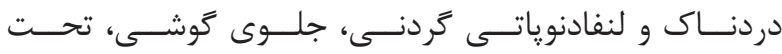

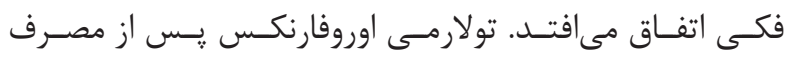

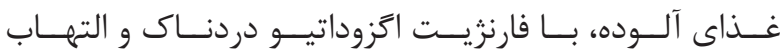

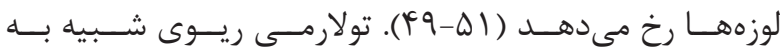

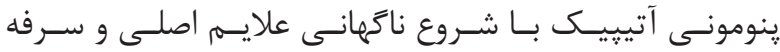

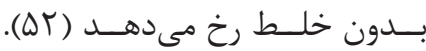

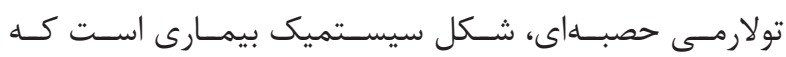

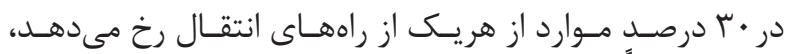

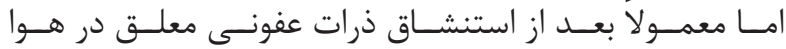

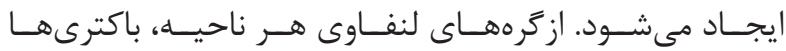

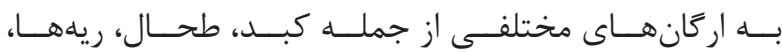

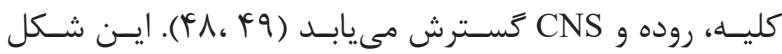

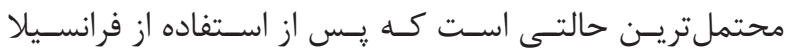

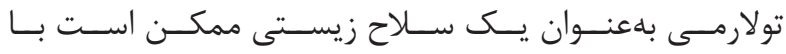

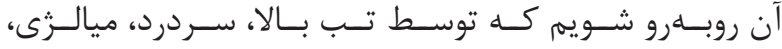

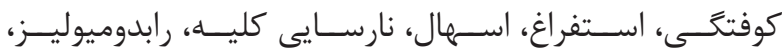

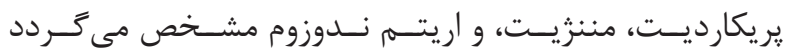

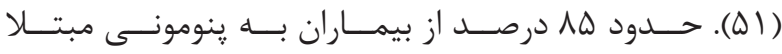

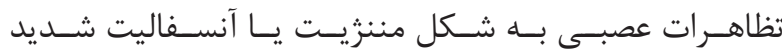

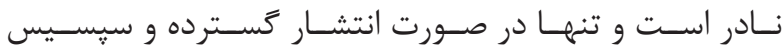
رن مىدهـــ (QT)

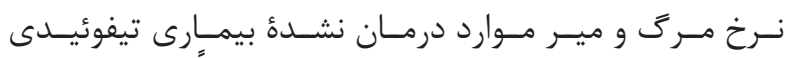

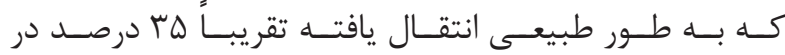




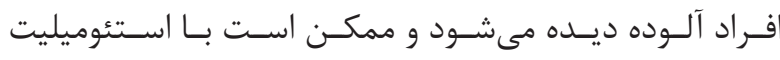

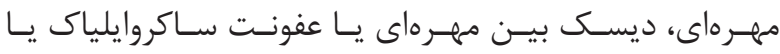

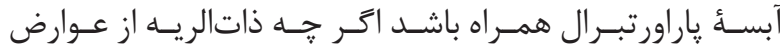

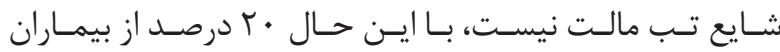

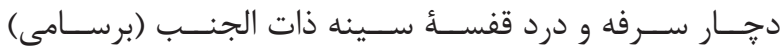

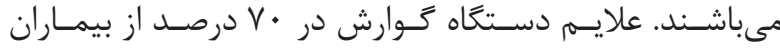

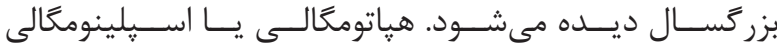

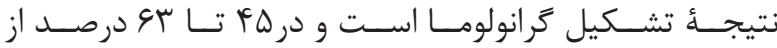

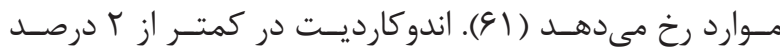

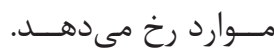

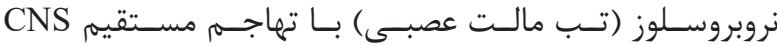

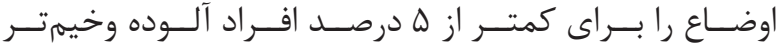

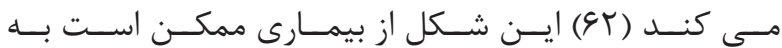

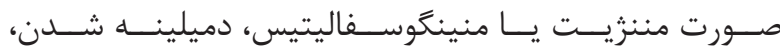

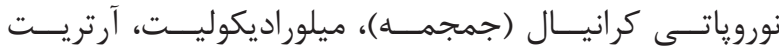

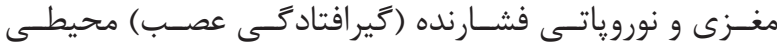

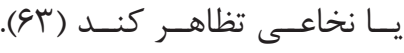

تشـخـيص شـامل كشـت خــون، آسِيراسـيون مغـز اسـتخوان

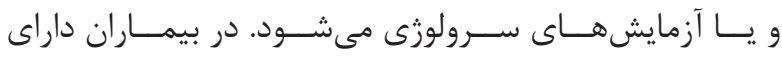

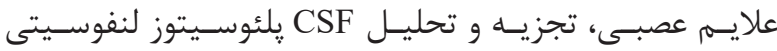

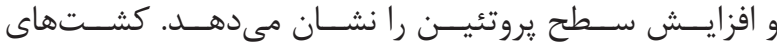

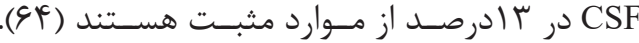

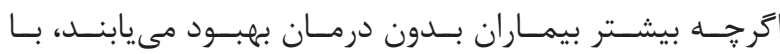

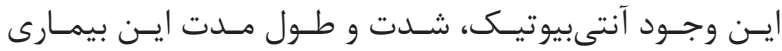

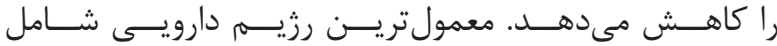

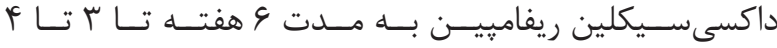

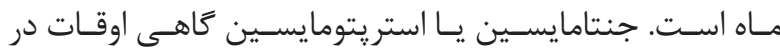

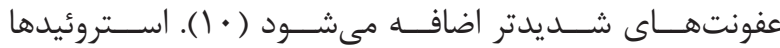

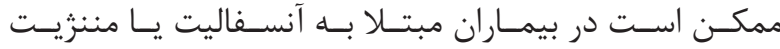

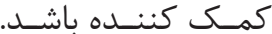

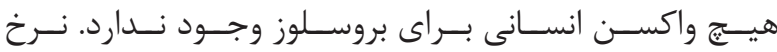

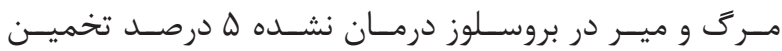

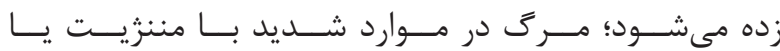

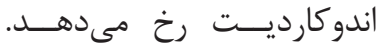

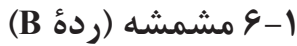

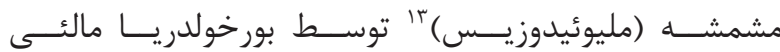

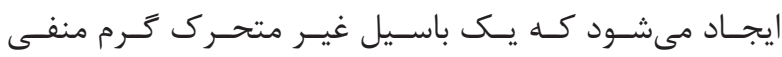

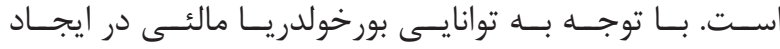

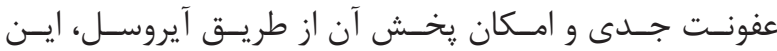

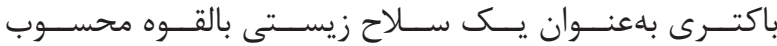

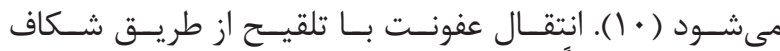

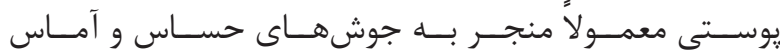

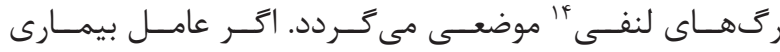

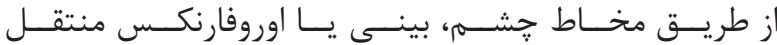

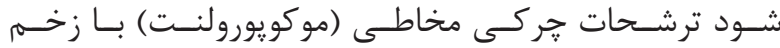

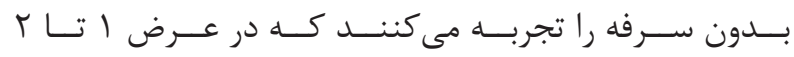

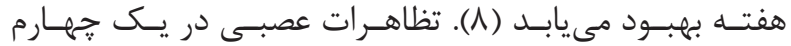

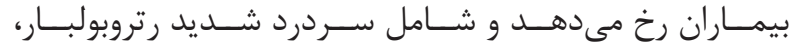

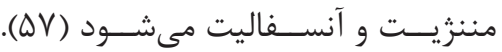

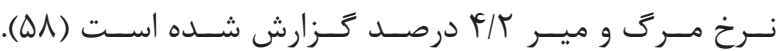

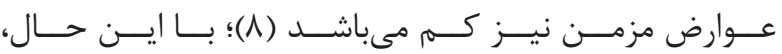

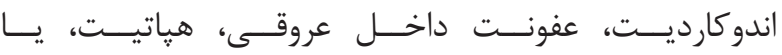

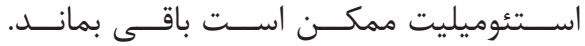

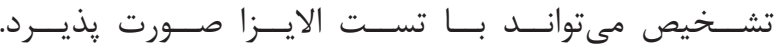

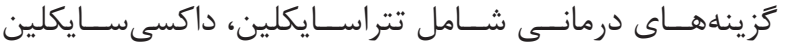

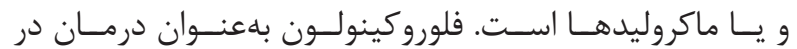

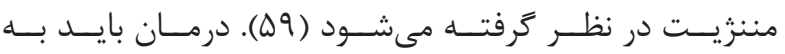

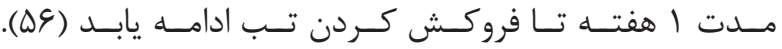

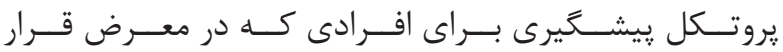

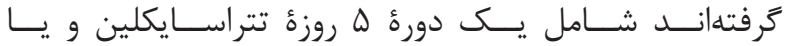

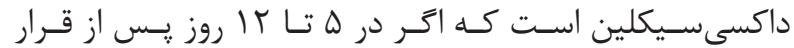

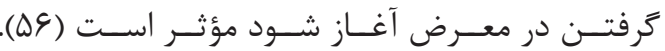

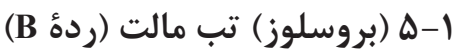

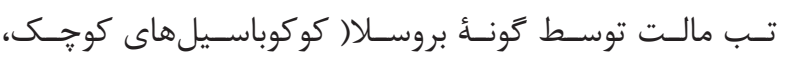

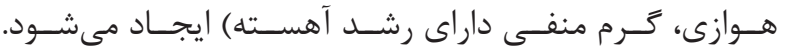

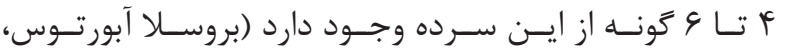

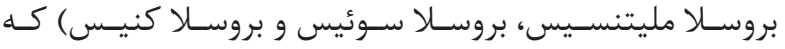

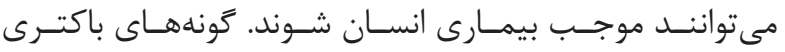

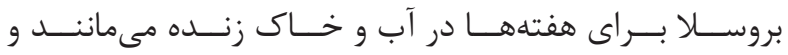

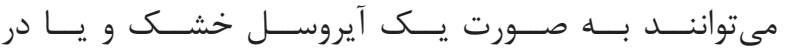

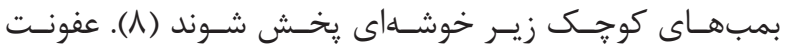

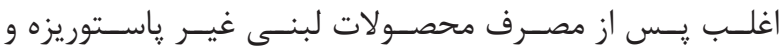

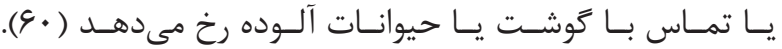

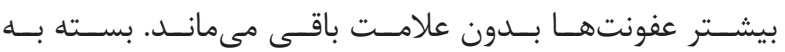

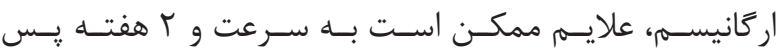

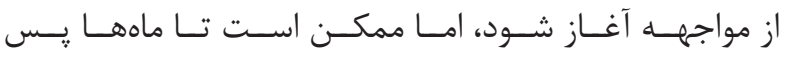

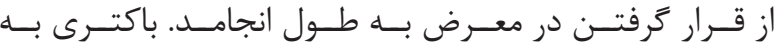

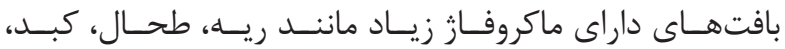

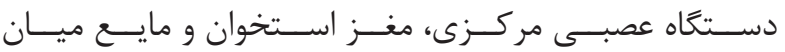

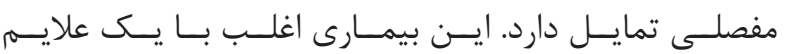

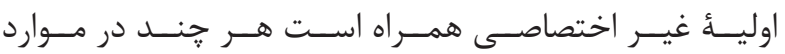

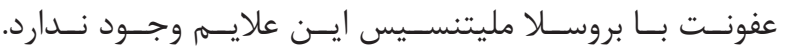

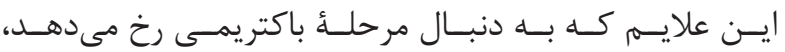

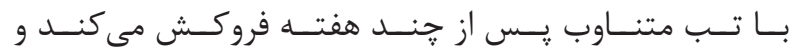

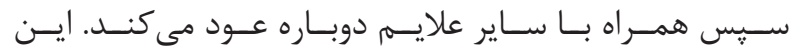

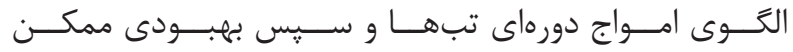

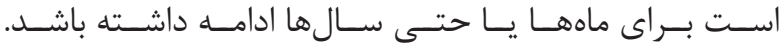

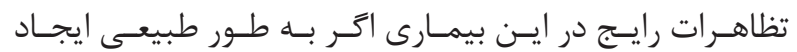

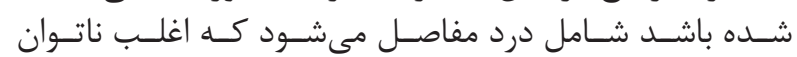

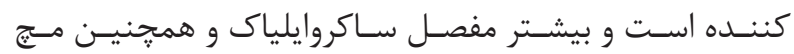

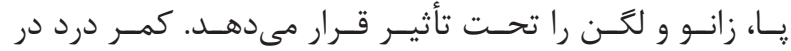




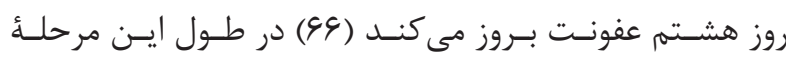

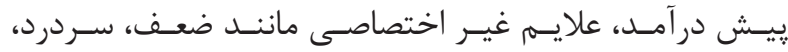

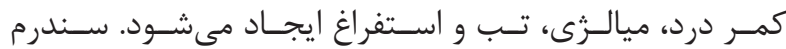

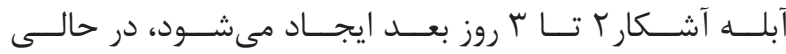

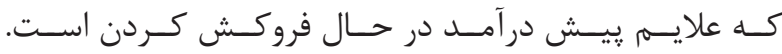

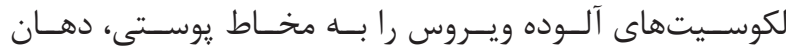

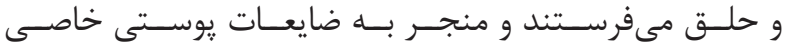

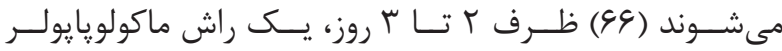

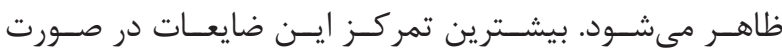

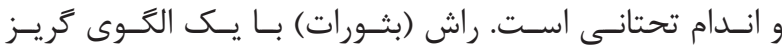

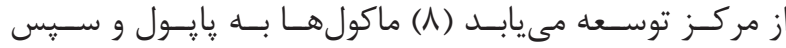

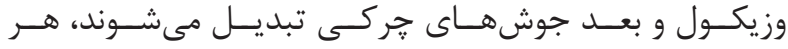

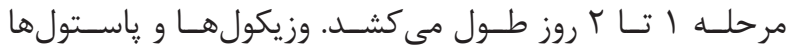

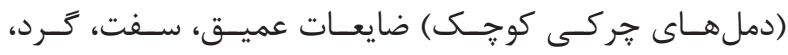

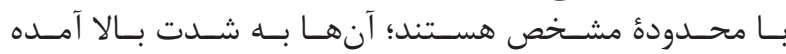

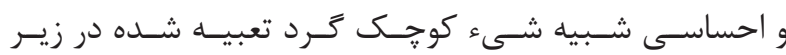

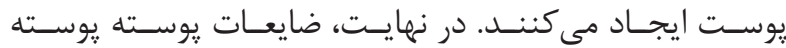

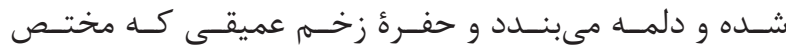

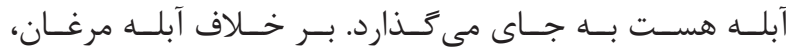

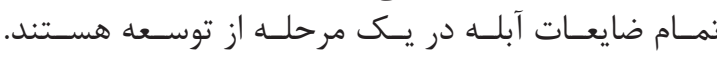

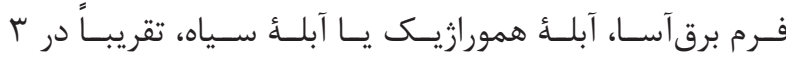

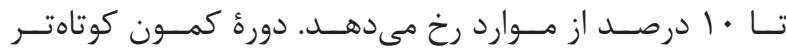

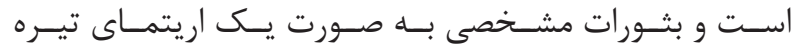

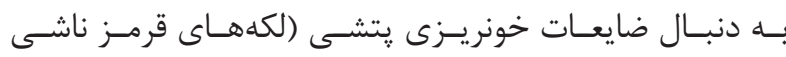

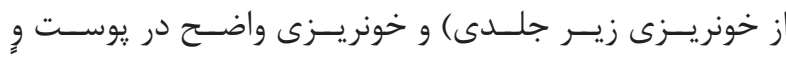

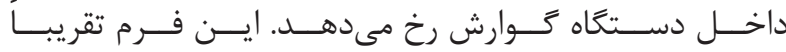

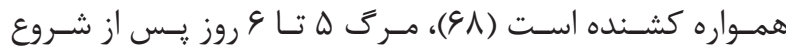

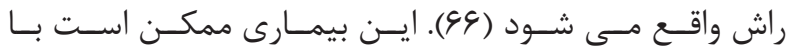

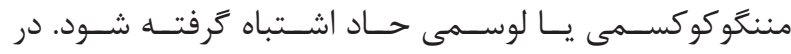

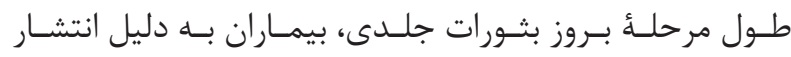

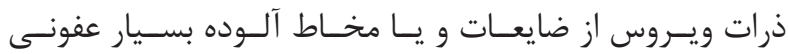

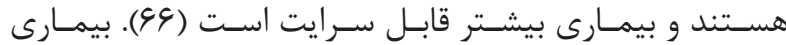

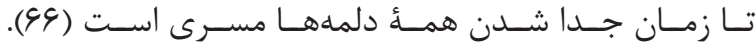

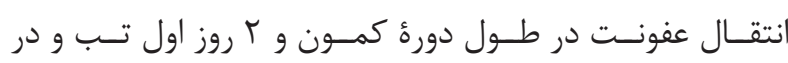

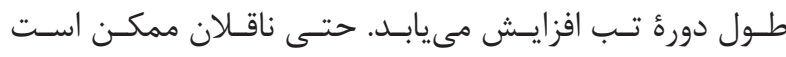

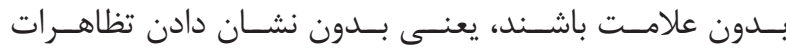

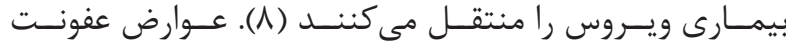

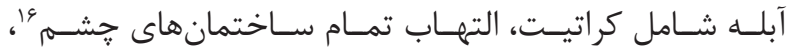

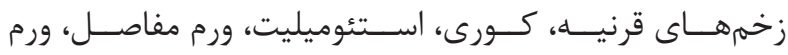
بيضـهـ و آنســفاليت مى كباشــــ (9 (9).

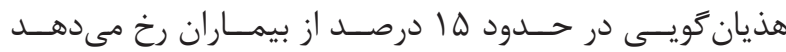

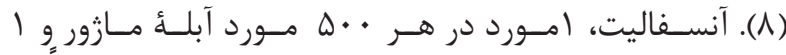

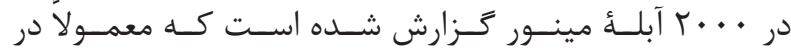

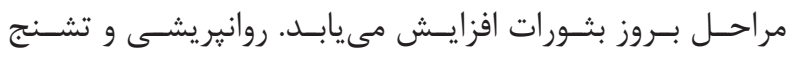

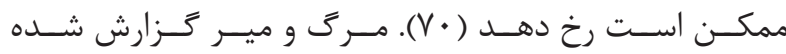

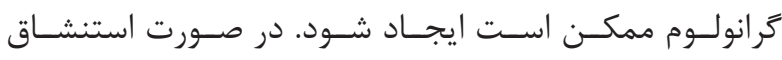

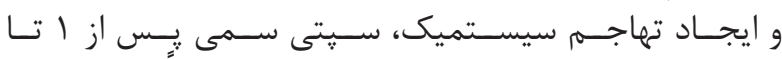

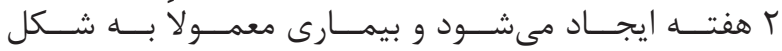

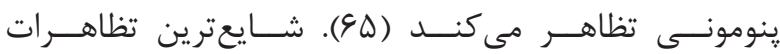

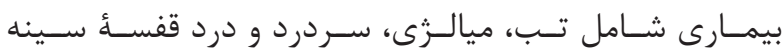

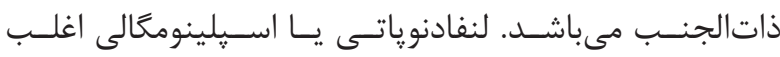

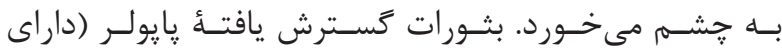

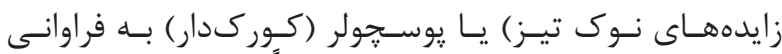

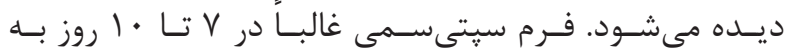

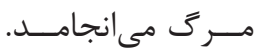

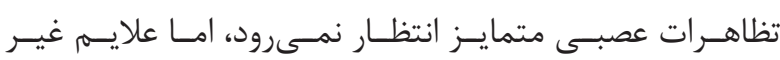

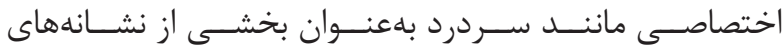
رايسج وجـون دارد.

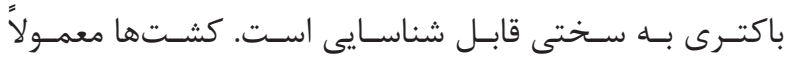

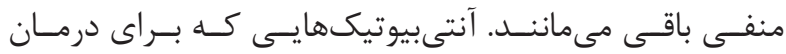

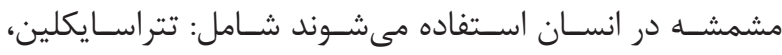

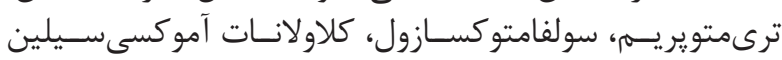

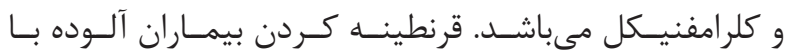

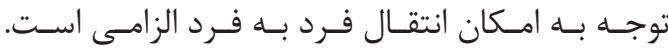

r- (- عوامل ويروسى

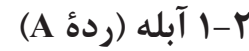

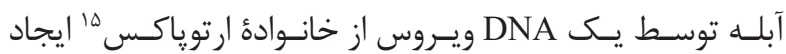

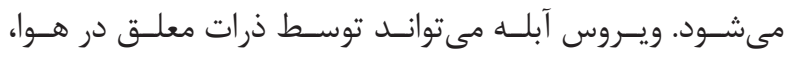

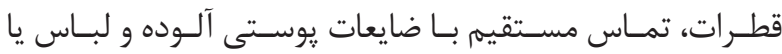

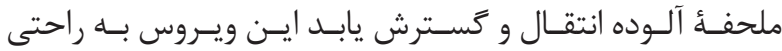

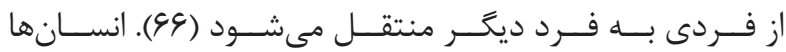

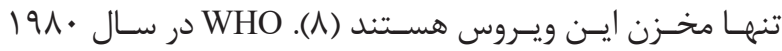

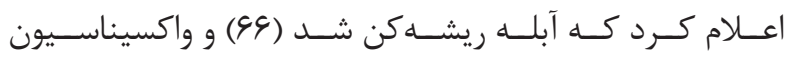

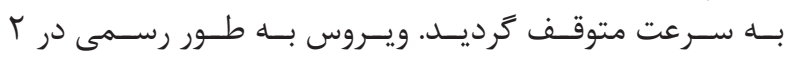

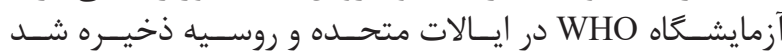

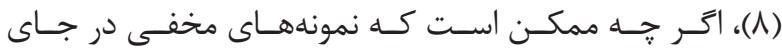

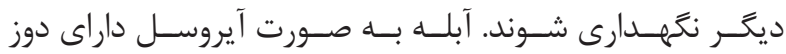

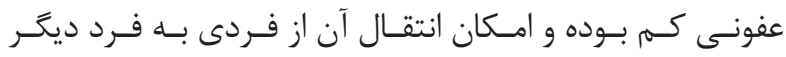

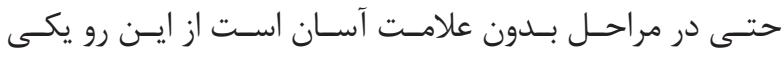

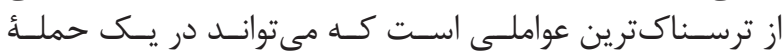
بيولوزيكسى اسـتفاده شـود (99، (9V).

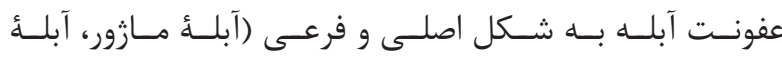

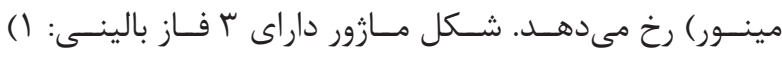

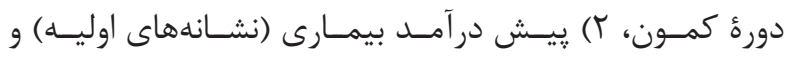

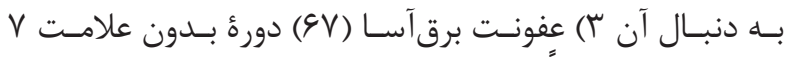

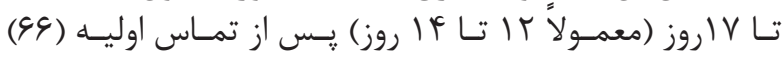

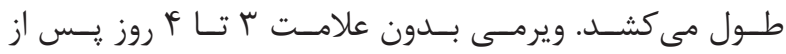

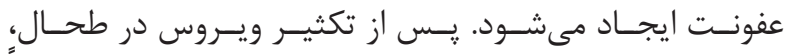

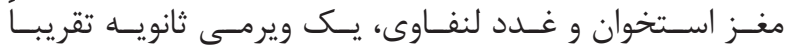




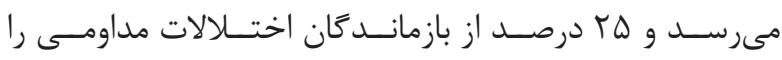

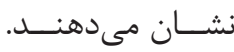

r-r تب خونريزى دهندهُ ويروسى

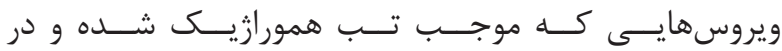

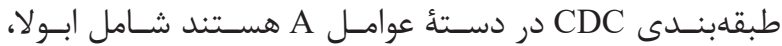

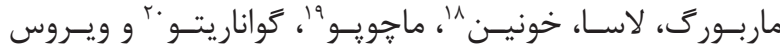

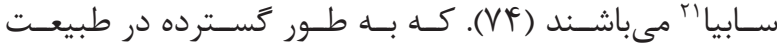

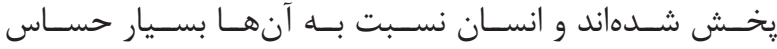

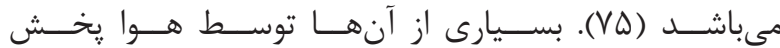

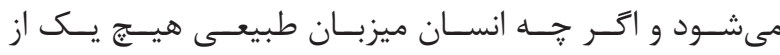

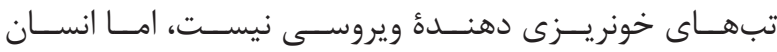

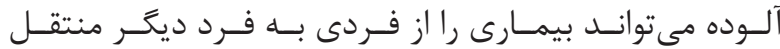

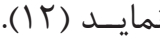

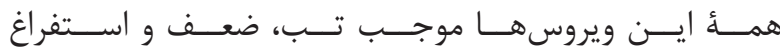

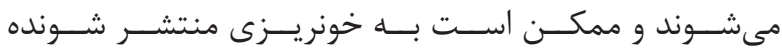

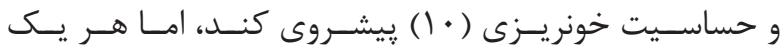

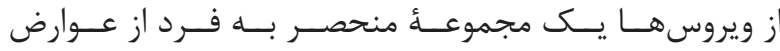

بالينــى را ايجــاد مىنماينـــ (VD).

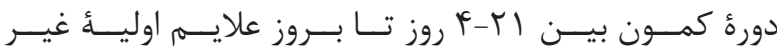

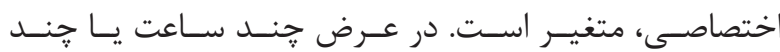

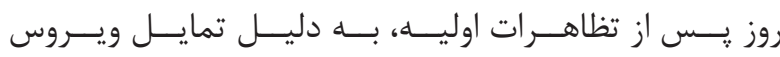

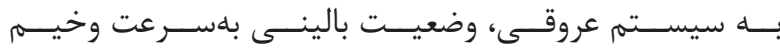

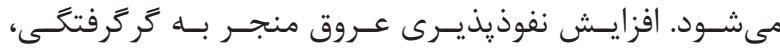

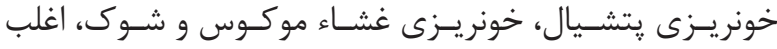

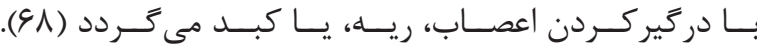

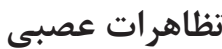

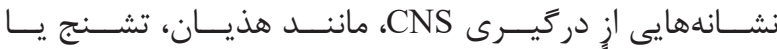

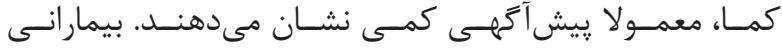

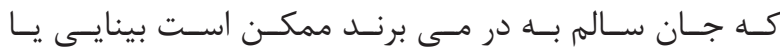

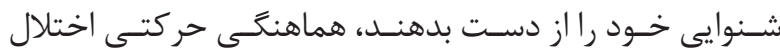

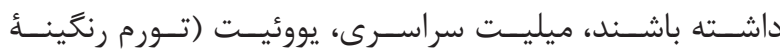

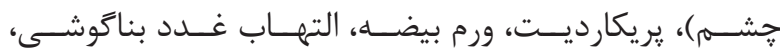

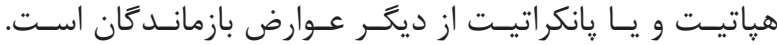

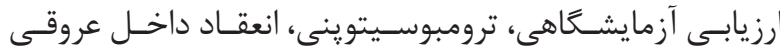

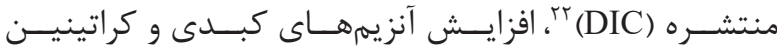

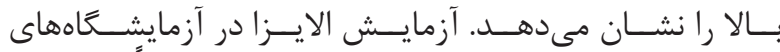

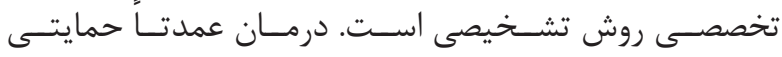

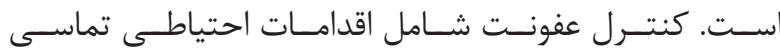

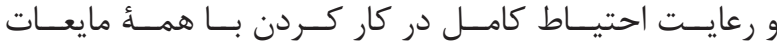

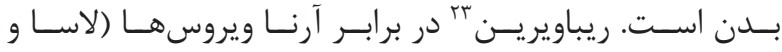

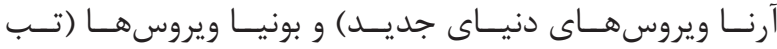

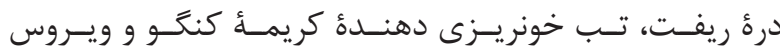

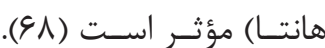

${ }^{17}$ Cidofovir

${ }^{18}$ Junin

${ }^{19}$ Machupo

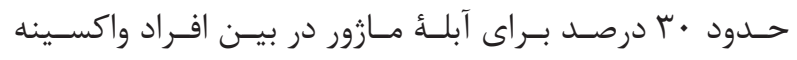

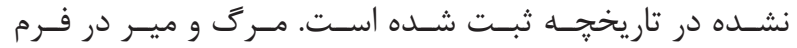

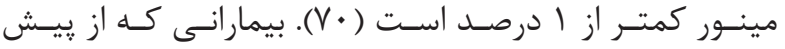

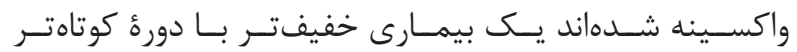

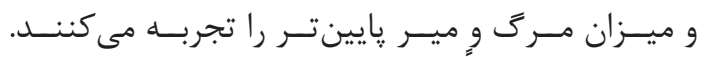

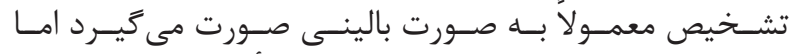

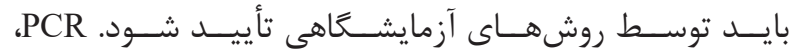

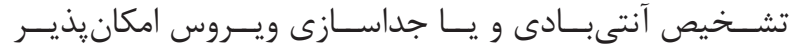

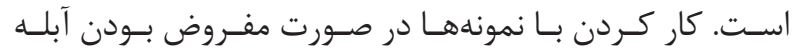

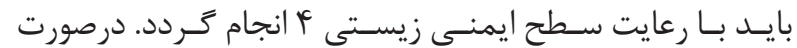

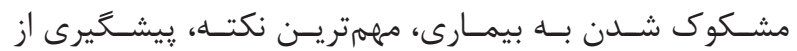

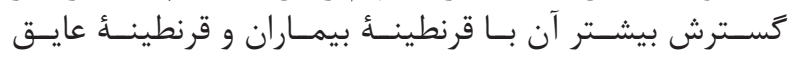

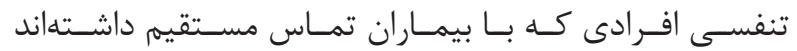

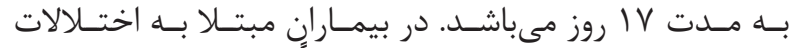

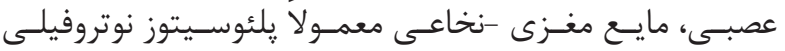

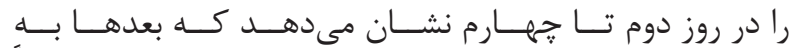

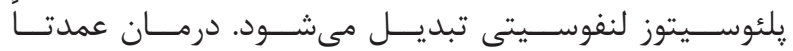

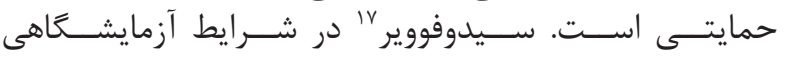

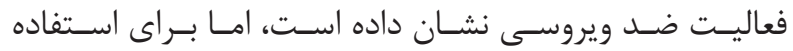

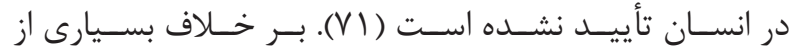

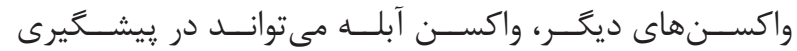

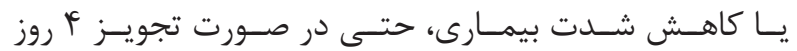

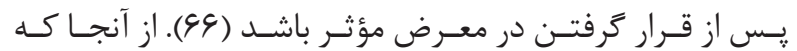

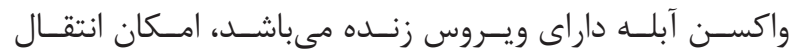

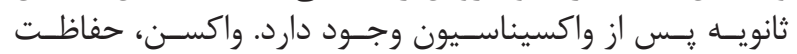

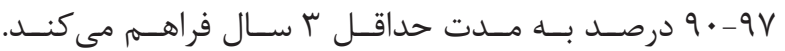

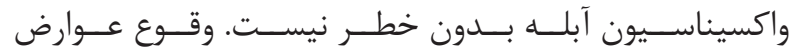

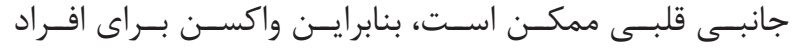

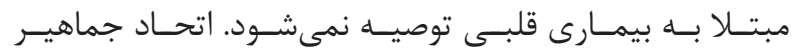

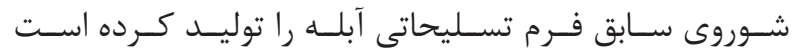

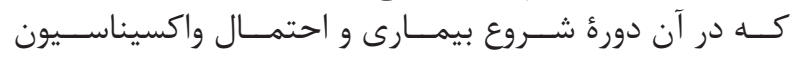

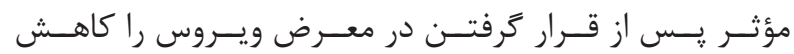
داده اسـت مؤستر (VT)

\section{عوارض عصبى ناشى از واكسيناسيون آبله}

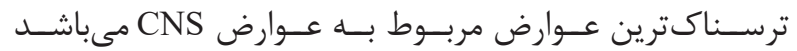

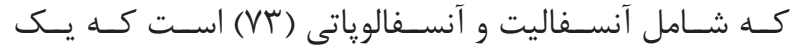

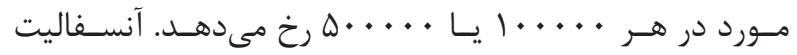

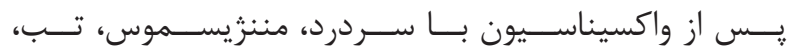

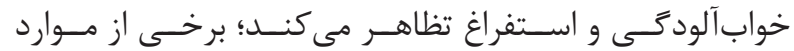

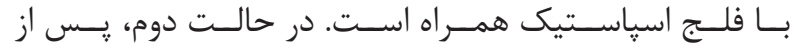

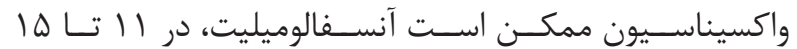

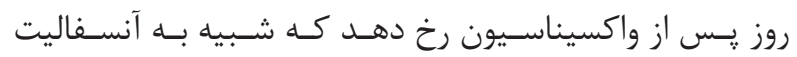

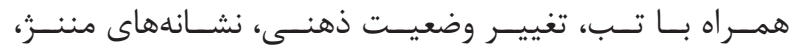

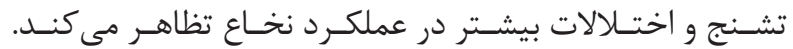

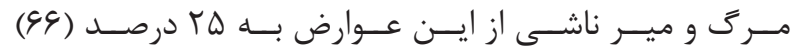

\footnotetext{
${ }^{20}$ Guanarito

${ }^{21}$ Sabia

${ }^{22}$ Disseminated intravascular coagulation
} 